\title{
Novel Lanthanide(III) Porphyrin-Based Metal-Organic Frameworks: Structure, Gas Adsorption, and Magnetic Properties
}

Nikolas Király, Vladimír Zeleňák,* Nina Lenártová, Adriana Zeleňáková, Erik Čižmár, Miroslav Almáši, Vera Meynen, Andrej Hovan, and Róbert Gyepes

Cite This: ACS Omega 2021, 6, 24637-24649

Read Online

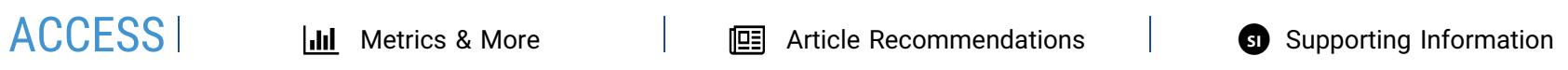

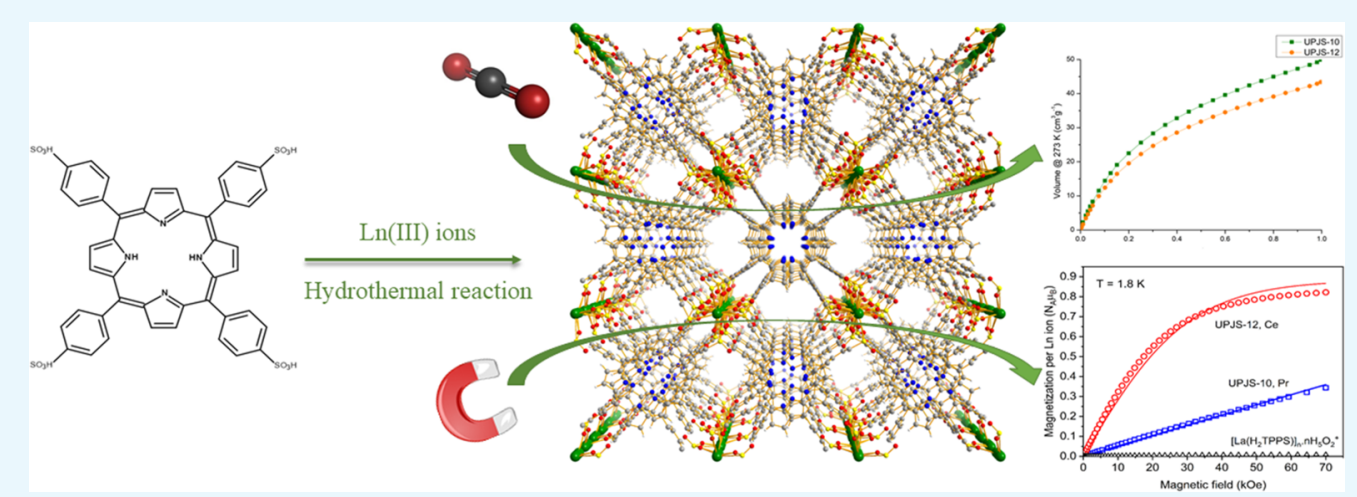

ABSTRACT: The present work focuses on the hydrothermal synthesis and properties of porous coordination polymers of metalporphyrin framework (MPF) type, namely, $\left\{\left[\mathrm{Pr}_{4}\left(\mathrm{H}_{2} \mathrm{TPPS}\right)_{3}\right] \cdot 11 \mathrm{H}_{2} \mathrm{O}\right\}_{n}$ (UPJS-10), $\left\{\left[\mathrm{Eu} / \mathrm{Sm}\left(\mathrm{H}_{2} \mathrm{TPPS}\right)\right] \cdot \mathrm{H}_{3} \mathrm{O}^{+} \cdot 16 \mathrm{H}_{2} \mathrm{O}\right\}_{n}(\mathrm{UPJS}-$ 11), and $\left\{\left[\mathrm{Ce}_{4}\left(\mathrm{H}_{2} \mathrm{TPPS}\right)_{3}\right] \cdot 11 \mathrm{H}_{2} \mathrm{O}\right\}_{n}$ (UPJS-12) $\left(\mathrm{H}_{2} \mathrm{TPPS}=4,4^{\prime}, 4^{\prime \prime}, 4^{\prime \prime \prime}\right.$-(porphyrin-5,10,15,20-tetrayl)tetrakisbenzenesulfonate(4)). The compounds were characterized using several analytical techniques: infrared spectroscopy, thermogravimetric measurements, elemental analysis, gas adsorption measurements, and single-crystal structure analysis (SXRD). The results of SXRD revealed a three-dimensional open porous framework containing crossing cavities propagating along all crystallographic axes. Coordination of $\mathrm{H}_{2}$ TPPS $^{4-}$ ligands with $\mathrm{Ln}(\mathrm{III})$ ions leads to the formation of $1 \mathrm{D}$ polymeric chains propagating along the $c$ crystallographic axis. Argon sorption measurements at $-186{ }^{\circ} \mathrm{C}$ show that the activated MPFs have apparent BET surface areas of $260 \mathrm{~m}^{2} \mathrm{~g}^{-1}$ (UPJS-10) and $230 \mathrm{~m}^{2} \mathrm{~g}^{-1}$ (UPJS-12). Carbon dioxide adsorption isotherms at $0{ }^{\circ} \mathrm{C}$ show adsorption capacities up to 1 bar of 9.8 wt $\%$ for UPJS-10 and $8.6 \mathrm{wt} \%$ for UPJS-12. At a temperature of $20^{\circ} \mathrm{C}$, the respective $\mathrm{CO}_{2}$ adsorption capacities decreased to 6.95 and 5.99 wt \%, respectively. The magnetic properties of UPJS-10 are characterized by the presence of a close-lying nonmagnetic ground singlet and excited doublet states in the electronic spectrum of $\operatorname{Pr}(\mathrm{III})$ ions. A much larger energy difference was suggested between the two lowest Kramers doublets of Ce(III) ions in UPJS-12. Finally, the analysis of X-band EPR spectra revealed the presence of radical spins, which were tentatively assigned to be originating from the porphyrin ligands.

\section{INTRODUCTION}

In the past three decades, porous metal-organic frameworks (MOFs) have been intensively studied because of the variety in potential applications in the fields of gas adsorption, ${ }^{1}$ drug delivery, ${ }^{2}$ energy cycles, ${ }^{3}$ photocatalysis and photoreduction, ${ }^{4}$ oxygen evolution reactions, ${ }^{5}$ sensing and explosive detection, ${ }^{6}$ and many others. Microporous crystalline MOFs are formed by the self-assembly of inorganic metal clusters and organic linkers. ${ }^{7}$ Both inorganic (metal clusters) and organic (ligands) constituents of MOFs can be varied in their shape, size, composition, geometry, and branching modality. This allows tuning of the structure and properties of MOFs to produce a versatile class of porous crystalline solids with a wide range of properties, high porosity, and surface area. Different polytopic ligands are being used ${ }^{8,9}$ to construct MOFs with desired topologies.

Excellent examples of polytopic ligands with great potential to serve as building blocks in MOF construction are porphyrins, metalloporphyrins, and their derivatives. These ligands offer rigidity and the possibility of a four-connecting symmetry. For a long time, porphyrin ligands have been overlooked in MOF chemistry, although examples of porous

Received: June 25, 2021

Accepted: August 20, 2021

Published: September 17, 2021 
MOFs based on porphyrins were known for a longer time. ${ }^{10}$ Extensive MOF research using porphyrinato ligands started after 2010 (see Figure 1). Although the porous structure of

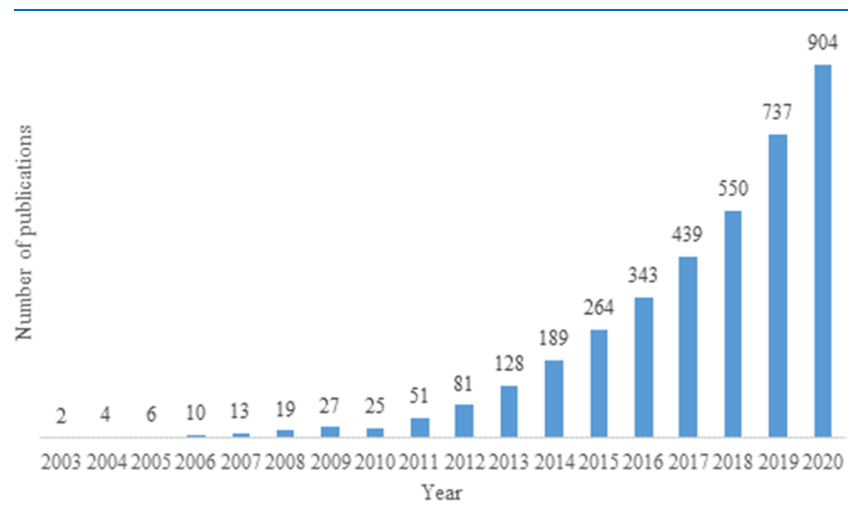

Figure 1. Number of publications from 2003 up to the present (January 2021) found in the Scopus database using the phrase "metal-organic frameworks and porphyrin".

some metal-porphyrin frameworks (MPFs) and metalmetalloporphyrin frameworks (MMPFs) often collapses after solvent removal, there are published examples where MMPFs maintain their structural integrity upon removal of solvents, forming stable and robust frameworks with a large void volume accessible to guest molecules. ${ }^{11,12}$ An excellent review about MMPF crystal structures, classification, and their applications in guest-molecule adsorption and separation, catalysis, nanothin films, and light harvesting was published by Gao et al. ${ }^{13}$ The MMPFs represent an interesting example of nature unity and they form a bridge between the lifeless and living nature. They are interesting from a materials chemistry point of view as the structure of some metal-metalloporphyrin frameworks can mimic inorganic zeolites. For example, the self-assembly of cobalt chloride and meso-tetra(4-carboxyphenyl)porphine leads to the formation of MMPF with the designation PIZA$1,{ }^{12}$ which imitates zeolite $4 \mathrm{~A}$. On the other hand, MMPFs are also interesting from a bioinorganic chemistry point of view, as porphyrins and their metal derivatives are essential components of biomolecules (chlorophyll, hemoglobin, vitamin B12, etc.). Different biochemical functions depend on the special properties of the porphyrin-derived macrocycle. The recent achievements and progress in the field of porphyrin-based MOFs for biomedical applications were published by Chen et al. ${ }^{14}$ Moreover, another review dealing with porphyrin and phthalocyanine metal-organic frameworks, their synthesis, structure, and topology was reported recently. ${ }^{15}$

As has been stated above, in the past 10 years, there has been a growing interest in metal-metalloporphyrin frameworks. The mentioned interest is evident from Figure 1, where results of the search in the Scopus database using the phrase "metal-organic frameworks and porphyrin" are summarized. In our recent works, we studied the preparation and properties of novel MOFs using polytopic flexible ligands with $T_{\mathrm{d}}$ symmetry, having four carboxylate groups available for metal coordination. ${ }^{16-20}$ As a continuation of our research, in the present work, we focused on the synthesis of novel MOFs using a rigid anionic ligand derived from 4,4', $4^{\prime \prime}, 4^{\prime \prime \prime}$ (porphyrin-5,10,15,20-tetrayl)tetrakis(benzenesulfonic) acid ( $\mathrm{H}_{6}$ TPPS) with 4-fold symmetry (point group $D_{4 v}$ ) (see Scheme 1).
Scheme 1. Molecular Structure of $4,4^{\prime}, 4^{\prime \prime}, 4^{\prime \prime \prime}$-(Porphyrin5,10,15,20-tetrayl)tetrakis(benzenesulfonic) Acid $\left(\mathrm{H}_{6}\right.$ TPPS) as an Organic Component Used in the Synthesis of UPJS-10 to UPJS-12 Materials

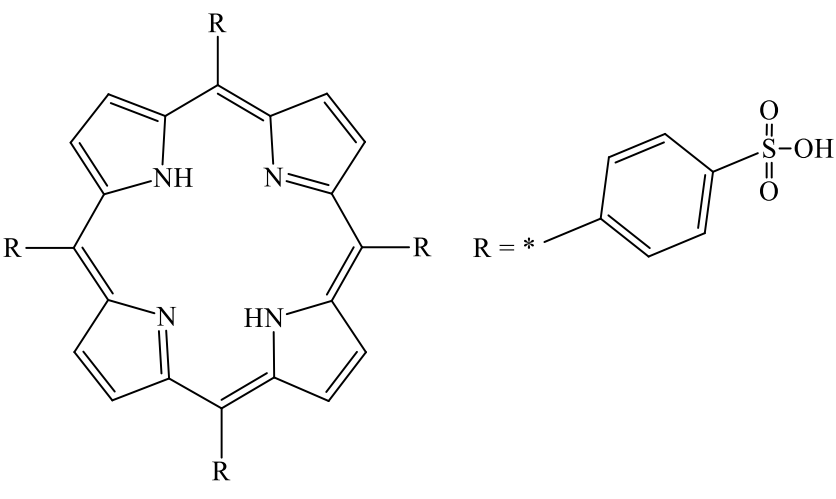

For the preparation of the MOFs in the present work, lanthanide cations ( $\mathrm{Ce}(\mathrm{III}), \operatorname{Pr}(\mathrm{III}), \mathrm{Eu}(\mathrm{III})$, and $\mathrm{Sm}(\mathrm{III})$ ) were used. The purpose of lanthanide ions in coordination polymers is of interest from a structural point of view due to their diversity in coordination numbers and stereochemistry but also from a practical use due to their interesting fluorescence and magnetic properties. ${ }^{21-23}$

To expand research on the compounds containing lanthanide ions represented by $\mathrm{Yi}$ et al. and Chen et al., ${ }^{24,25}$ we describe in the present work the preparation and properties of praseodymium(III), cerium(III), and a combination of europium(III)/samarium(III)-based MOFs, containing $\mathrm{H}_{2}$ TPPS $^{4-}$ anions, namely, $\left\{\left[\mathrm{Pr}_{4}\left(\mathrm{H}_{2} \mathrm{TPPS}\right)_{3}\right] \cdot 11 \mathrm{H}_{2} \mathrm{O}\right\}_{n}$ (UPJS-10), $\left\{\left[\mathrm{Eu} / \mathrm{Sm}\left(\mathrm{H}_{2} \text { TPPS }\right)\right] \cdot \mathrm{H}_{3} \mathrm{O}^{+} \cdot 16 \mathrm{H}_{2} \mathrm{O}\right\}_{n}$ (UPJS-11), and $\left\{\left[\mathrm{Ce}_{4}\left(\mathrm{H}_{2} \mathrm{TPPS}\right)_{3}\right] \cdot 11 \mathrm{H}_{2} \mathrm{O}\right\}_{n}$ (UPJS-12). Mentioned compounds contain lanthanide ions coordinated to sulfate arms of $\mathrm{H}_{2}$ TPPS $^{4-}$ ligands under the formation of final 3D polymeric frameworks. To the best of our knowledge, MOFs containing $\mathrm{H}_{2}$ TPPS $^{4-}$ anions without a metal coordinated to the nitrogen atoms of the tetrapyrrole are relatively rare, and only a few compounds have been structurally characterized. ${ }^{24-27}$ The compounds UPJS-10 and UPJS-12 were investigated for gas adsorption (argon and carbon dioxide), and their magnetic properties and reactive oxygen scavenging activity were also studied.

\section{RESULTS AND DISCUSSION}

Description of the Structures. It is well known that a planar porphyrin ligand can coordinate to metal ions through four nitrogen atoms of the four pyrrole rings. This coordination is accompanied by the loss of the two inner $\mathrm{NH}$ protons and depends mainly on the available space in the porphyrin core and the ionic radius of the metal ion. The van der Waals lengths of the interporphyrin cavities are approximately 4.0 to $5.24 \AA{ }^{28}$ while the radius of the porphyrin core is about 7-9 $\AA^{29}$ For $3 \mathrm{~d}$ metals, their ionic radius coincides with the available space of the porphyrin core, leading to metal coordination into the porphyrin cavity and a planar geometry with the porphyrin. However, when coordinating larger ions such as $4 \mathrm{~d}$ and $5 \mathrm{~d}$ or inner transition metals, the metal ion is usually located outside the porphyrin plane, or the porphyrin cavity remains empty, without metal coordination. ${ }^{29,30}$ In the case for the complexes UPJS-10, UPJS-11, and UPJS-12 where large $\operatorname{Pr}(\mathrm{III}), \mathrm{Eu} / \mathrm{Sm}$ (III), and $\mathrm{Ce}$ (III) ions are not coordinated in the porphyrin ring but to 


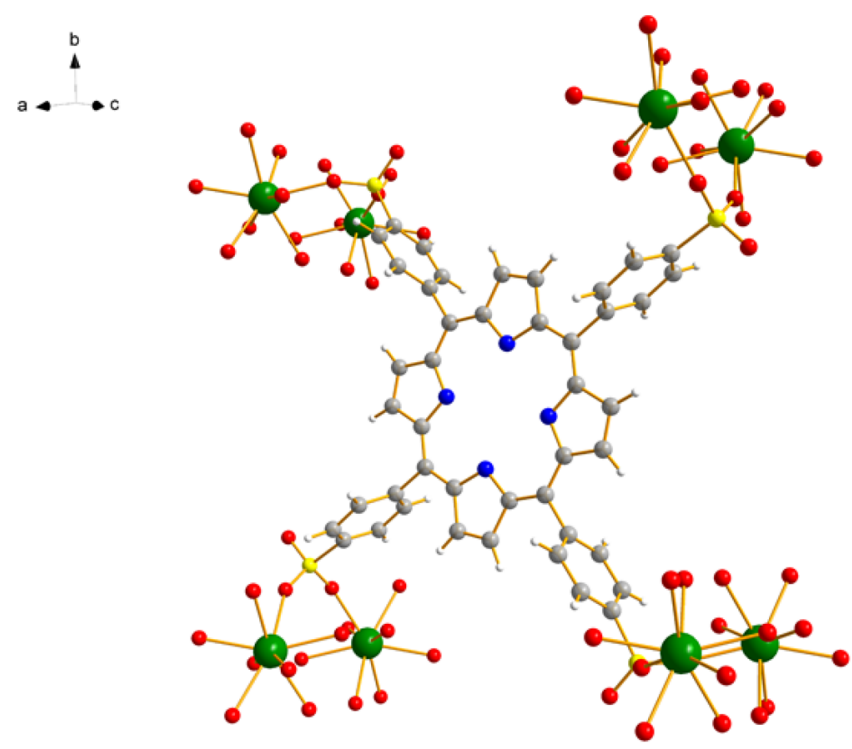

a)

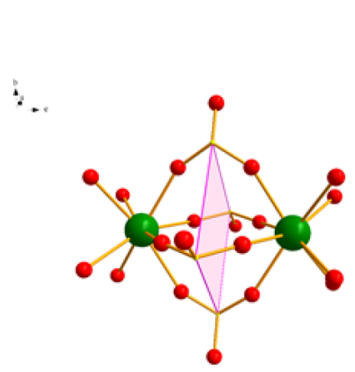

b)

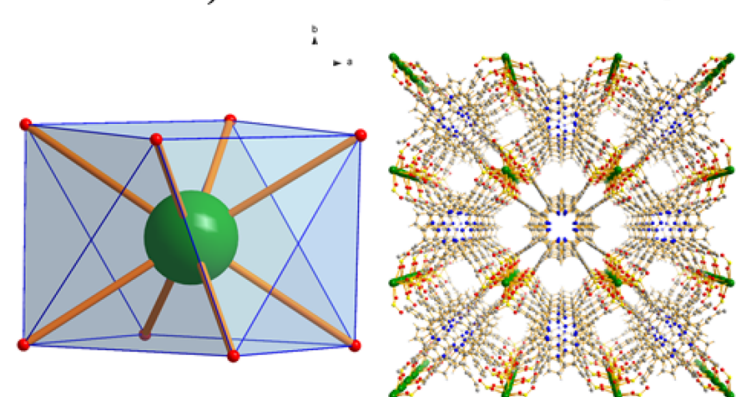

c) d)

Figure 2. (a) Coordination modes of $\mathrm{H}_{2} \mathrm{TPPS}^{4-}$ to $\mathrm{Pr}(\mathrm{III})$ ions in the crystal structure of $\left\{\left[\mathrm{Pr}_{4}\left(\mathrm{H}_{2} \mathrm{TPPS}\right)_{3}\right] \cdot n \mathrm{H}_{2} \mathrm{O}\right\}_{n}$. (b) View of the -Pr- $\left(\mathrm{SO} \mathrm{O}_{3}\right)_{4}{ }^{-}$ Pr- cluster, forming $1 \mathrm{D}$ chains propagating along the $c$ crystallographic axis, with the representation of a square planar SBU, (c) square antiprismatic coordination geometry of $\operatorname{Pr}(\mathrm{III})$ ions in UPJS-10, and (d) 3D porous framework viewed along the $c$ crystallographic axis.

the external sulfonate groups of the $\mathrm{H}_{2} \mathrm{TTPS}^{4-}$ anions, the sulfonate groups of $\mathrm{H}_{6}$ TPPS are thus deprotonated, leaving only the two remaining $\mathrm{NH}$ protons in the ligand $\mathrm{H}_{2} \mathrm{TPPS}^{4-}$. The yield during the syntheses was relatively low. We suppose that this can be due to the low stability of the prepared compounds in solution, as reported recently. ${ }^{15} \mathrm{We}$ tried different synthetic conditions during the syntheses; however, the yield was low in all attempts.

The synthesized compounds UPJS-10, UPJS-11, and UPJS12 have similar crystal structures, and for this reason, we will describe only the crystal structure of the complex UPJS-10 in detail. The detailed crystallographic parameters, including bond lengths and angles of UPJS-10, UPJS-11, and UPJS-12, are summarized in Tables $\mathrm{S} 1-\mathrm{S} 4$ in the Supporting Information. The crystal structure of UPJS-10 is shown in Figure 2a. The single-crystal X-ray diffraction study revealed that the complex crystallizes in a tetragonal system with the space group $P 4 / m c c$, with $a=15.3898(5) \AA, b=15.3898$ (5) $\AA$, and $c=9.9474(6) \AA$, with eight formula units in the cell. In the compound UPJS-10, all four sulfonic acid $-\mathrm{SO}_{3} \mathrm{H}$ groups of the native $\mathrm{H}_{6}$ TPPS ligand used in the synthesis are deprotonated, while two porphyrin hydrogens are still present in the cavity, which is supported by the presence $\nu(\mathrm{N}-\mathrm{H})$ vibrations in the DRIFT infrared spectrum (see Figures $S 1$ and $\mathrm{S} 2$ in the Supporting Information). The $\mathrm{H}_{2} \mathrm{TPPS}^{4-}$ ligand, as a 24-membered macrocyclic ring, displays a characteristic planar conformation. The angle between the mean least-squares plane formed by the four pyrrole rings and planes formed by the benzenesulfonic group has an ideal $90^{\circ}$. The neighboring porphyrin macrocyclic planes are parallel along the $c$ crystallographic axis with a distance of $4.9835 \AA$. The Pr(III) ions are eight-coordinated, with the eight oxygen atoms originating from eight independent sulfonate ligands (see Figure $2 \mathrm{~b}$ ), resulting in a deformed square antiprismatic coordination geometry for the $\operatorname{Pr}(\mathrm{III})$ ion (see Figure $2 \mathrm{c}$ ). The sulfonate ligands interconnect the neighboring $\operatorname{Pr}(\mathrm{III})$ ions, forming $\operatorname{Pr}-\left(\mathrm{SO}_{3}\right)_{4}$-Pr- dimers along the $c$ crystallographic axis, with a $\operatorname{Pr}(\mathrm{III}) \cdots \operatorname{Pr}(\mathrm{III})$ distance of $4.98 \AA$ (see Figure $2 \mathrm{~b}$ ). The average bond length of $\mathrm{Pr}-\mathrm{O}$ is $2.438 \AA$, which is in the standard range and comparable with similar compounds documented in the literature. The coordination motif of the dimer resembles a paddle-wheel geometry, which is well known and often occurs in metal carboxylates.

The propagation of mentioned dimer along the $c$ axis results in the formation of one-dimensional infinite chains in the final crystal structure of UPJS-10. By creating a link between the sulfur atoms of the coordinated sulfonate groups in the Pr$\left(\mathrm{SO}_{3}\right)_{4}$-Pr- dimers, square planar secondary building blocks (SBUs) are formed (see Figure 2b). Furthermore, the coordination of $\mathrm{H}_{2} \mathrm{TPPS}^{4-}$ ligand to the eight $\operatorname{Pr}(\mathrm{III})$ ions leads to the formation of the final three-dimensional porous framework (see Figure 2d) containing three mutually crossing 
cavities propagating along all crystallographic axes with sizes of approximately $4.97 \times 5.45 \AA^{2}$ (along $a$ and $b$ crystallographic axes) and $8.22 \times 8.37 \AA^{2}$ (along the $c$ crystallographic axis). Due to the long average distance between porphyrin rings (5.21(3) $\AA$ ), there are no $\pi-\pi$ stacking interactions in the structure. The hydrogen bond formed by water molecules could not be characterized due to the high disorder of water molecules.

Moreover, in the crystal structure of UPJS-10, water of crystallization molecules are present in the cavities. These molecules could not be determined unambiguously by singlecrystal XRD analysis due to the high disorder, but their presence and quantity were derived from the combination of IR, TGA, and elemental analysis results (see the section below). When considering the solvent removal and using the PLATON/SQUEEZE tool, a total free pore volume of $476 \AA^{3}$ was found in the structure of the compound UPJS-10, which represents $20.2 \%$ of free space based on the cell volume (2356 $\left.\AA^{3}\right)$. Using the ToposPro program, ${ }^{31}$ an analysis of the UPJS10 framework was performed, which showed that the compound does not imitate any known mineral and is unique. The analysis showed that the framework has a $3^{2}, 6-c$ net topology using standard representation of the covalent compounds. However, if the cluster is considered as a single node representation, then the framework of the compound can be described as fsc-net. ${ }^{32,33}$

Compounds with stoichiometry similar to UPJS-10 and similar coordination mode of the $\mathrm{H}_{2}$ TPPS $^{4-}$ ligand but containing the different ions have already been published. Chen et al. ${ }^{34}$ described a terbium-containing complex with the composition $\left[\mathrm{Tb}\left(\mathrm{H}_{2} \mathrm{TPPS}\right) \cdot \mathrm{H}_{3} \mathrm{O} \cdot 2 \mathrm{H}_{2} \mathrm{O}\right]_{n}$. The terbium ion is surrounded by eight oxygen atoms of sulfonate groups, yielding a distorted square antiprism. Each terbium ion connects eight $\mathrm{H}_{2}$ TPPS $^{4-}$ moieties to complete a $3 \mathrm{D}$ porous open framework with the channels running along the $c$ axis. ${ }^{34}$ The samarium(III) compound $\left[\mathrm{Sm}\left(\mathrm{H}_{3} \mathrm{TPPS}\right)\right]_{n} \cdot n \mathrm{H}_{2} \mathrm{O}$ with the protonated porphyrin ligand was reported by Chen et al. ${ }^{35}$ The $\mathrm{Sm}$ (III) ion is eight-coordinated by eight $\mathrm{O}$ atoms of eight individual porphyrinato ligands, which resemble a slightly distorted square antiprism. To keep charge balance, the authors state that one nitrogen atom of the macrocyclic porphyrin core must be protonated, forming an $\mathrm{H}_{3}$ TPPS $^{3-}$ moiety. ${ }^{35}$ However, in another work, ${ }^{24}$ a similar $\mathrm{Sm}$ (III) compound is considered with the $\mathrm{H}_{2}$ TPPS $^{4-}$ ligand and the stoichiometry [Sm(TPPS) $]_{n} \cdot n \mathrm{H}_{5} \mathrm{O}_{2}$.

The stoichiometry of the compound UPJS-11 differs from that of UPJS-10, but the crystal structure is similar. The compound UPJS-11 (see Figure S3 in the Supporting Information) has a chemical formula $\left\{\left[\mathrm{Eu} / \mathrm{Sm}\left(\mathrm{H}_{2} \mathrm{TPPS}\right)\right]\right.$. $\left.n \mathrm{H}_{3} \mathrm{O}^{+} \cdot n \mathrm{H}_{2} \mathrm{O}\right\}_{n}$ and consists of the ligand $\mathrm{H}_{2}$ TPPS $^{4-}$ and $\mathrm{Sm}(\mathrm{III})$ and $\mathrm{Eu}$ (III) cations in the molar ratio of $60: 40$, respectively. The ratio of metal cations in the structure UPJS11 was confirmed by EDS analysis, which determined the atomic percentage of used metals in randomly studied scan sectors (see Table S5 and Figure S4 in the Supporting Information). The coordination polymer UPJS-11 crystallizes in a tetragonal crystallographic system with the $P 4 / m c c$ space group, similar to the coordination polymer UPJS-10. In UPJS11, the structural characteristics, connectivity, and the crystal structure description are similar to the compound UPJS-10. The $\mathrm{H}_{2}$ TPPS $^{4-}$ anions interconnect the neighboring $\mathrm{M}(\mathrm{III})$ ions $(\mathrm{M}=\mathrm{Eu}(\mathrm{III})$ and $\mathrm{Sm}(\mathrm{III}))$, and this bringing coordination creates $\mathrm{M}$ - $\left(\mathrm{SO}_{3}\right)_{4}-\mathrm{M}$ - dimers along the $c$ crystallographic axis, with a distance of $4.93 \AA$ between $\mathrm{M}(\mathrm{III}) \cdots \mathrm{M}(\mathrm{III})$ ions. The $\mathrm{M}(\mathrm{III})$ ions are coordinated with eight oxygen atoms, which create a deformed square antiprismatic coordination geometry. The sizes of cavities along crystallographic axes of UPJS-11 are approximately 4.92 $\times 5.46 \AA^{2}$ (along $a$ and $b$ crystallographic axes) and $8.28 \times$ $8.18 \AA^{2}$ (along the $c$ crystallographic axis). In the cavities, water of crystallization molecules could not be refined precisely by XRD analysis due to the high disorder. The amount of water molecules was determined from elemental and thermal analyses. Using the PLATON/SQUEEZE tool, a total free pore volume of $464 \AA^{3}$ was found, representing 19.9\% of free space based on the cell volume $\left(2332 \AA^{3}\right)$. For the compound UPJS-11, only a few crystals could be prepared. Therefore, only the X-ray single-crystal structure determination, infrared spectra, and elemental analysis were performed for this compound.

A similar stochiometry and coordination geometry of building blocks found in UPJS-11 were also observed for a series of three isostructural complexes of the composition $[\mathrm{Ln}(\mathrm{TPPS})]_{n} \cdot n \mathrm{H}_{5} \mathrm{O}_{2}{ }^{+}$(where $\mathrm{Ln}=\mathrm{La}, \mathrm{Sm}$, and $\mathrm{Eu}$ and $\mathrm{H}_{5} \mathrm{O}_{2}{ }^{+}$ $\left.=\mathrm{H}_{3} \mathrm{O}^{+}+\mathrm{H}_{2} \mathrm{O}\right) \cdot{ }^{24}$ However, in these compounds, only a $1 \mathrm{D}$ channel system, along the crystallographic $c$ axis, was observed in contrast to the three mutually interconnected channels along all three crystallographic axes in UPJS-11. Similar building blocks located in UPJS-11 (Eu ion and $\mathrm{H}_{6}$ TPPS ligand) were found in the coordination polymer $\mathrm{Eu}_{2}(\mathrm{OH})_{4.7}(\mathrm{TPPS})_{0.33} \cdot 2 \mathrm{H}_{2} \mathrm{O} \cdot{ }^{36}$ However, the crystal structure of this compound is different and is composed of distorted octahedral oxometalate clusters $\left[\mathrm{Eu}_{6}\left(\mu_{6}-\mathrm{O}\right)\left(\mu_{3}\right.\right.$ $\left.\mathrm{OH})_{8}\left(\mathrm{H}_{2} \mathrm{O}\right)_{14}\right]^{8+}$. Such SBU units are linked together by six distorted porphyrin units and the central oxygen atom is coordinated to six europium atoms connected via eight $\mathrm{OH}$ groups. $^{36}$

The last synthesized compound, UPJS-12 (see Figure S5 in the Supporting Information), contains the Ce(III) cations and $\mathrm{H}_{2}$ TPPS $^{4-}$ linkers. Although during the synthesis, Ce(IV) salt was used, $\mathrm{Ce}(\mathrm{IV})$ cations were reduced to $\mathrm{Ce}(\mathrm{III})$ as shown by magnetic and EPR measurements (see text below). Redox properties linked to $\mathrm{Ce}(\mathrm{IV}) / \mathrm{Ce}(\mathrm{III})$ redox pairs are well known. The reduction of $\mathrm{Ce}(\mathrm{IV})$ to $\mathrm{Ce}(\mathrm{III})$ in our reaction was probably induced by the negative redox potential of the porphyrin system, as reported elsewhere. ${ }^{34}$ The porous coordination polymer UPJS-12 has unit cell dimensions, $a=$ 15.4360 (3) $\AA, b=15.4360$ (3) $\AA$, and $c=10.0140$ (5) $\AA$, and is crystallized in a tetragonal system with the space group $P 4 /$ $m c c$. The Ce(III) ions are also eight-coordinated with the eight oxygen atoms from the sulfonate groups and form $\mathrm{Ce}-\left(\mathrm{SO}_{3}\right)_{4}$ $\mathrm{Ce}$ - dimers propagating along the $c$ crystallographic axis with a distance between $\mathrm{Ce}(\mathrm{III}) \cdots \mathrm{Ce}(\mathrm{III})$ ions of $5.07 \AA$. The coordination of eight $\mathrm{Ce}(\mathrm{III})$ ions to the $\mathrm{H}_{2} \mathrm{TPPS}^{4-}$ ligand leads to a condensed three-dimensional porous framework, containing three mutually crossing cavities propagating along all crystallographic axes with sizes of approximately $5.03 \times 5.07$ $\AA^{2}$ (along $a$ and $b$ crystallographic axes) and $8.17 \times 8.19 \AA^{2}$ (along the $c$ crystallographic axis). According to the PLATON/SQUEEZE analysis, the structure has a total free pore volume of $491 \AA^{3}$, representing $20.6 \%$ of free space based on the cell volume $\left(2386 \AA^{3}\right)$.

The crystallinity and bulk composition of the as-synthesized compounds were studied by powder X-ray diffraction. The obtained PXRD patterns are presented in Figure S6 (see the Supporting Information). Figure S6 shows the comparison of 
the experimental PXRD patterns and the ones calculated from the single-crystal X-ray data. Both patterns are almost identical, evidencing the phase purity of the prepared samples. The differences in the intensities of diffraction lines can be attributed to the variation in the preferred orientation of the crystallites in the analyzed powdered materials.

FT-IR and UV-VIS Spectral Study and Reactive Oxygen Scavenging. The infrared spectra of all the prepared compounds are shown in Figure S7 in the Supporting Information. In the infrared spectra, high similarities between UPJS-10, UPJS-11, and UPJS-12 samples were observed. Therefore, we describe the FT-IR spectrum of UPJS-10 in detail as an example. The spectrum exhibits a broad band centered at $3414 \mathrm{~cm}^{-1}$, which can be attributed to the $\mathrm{O}-\mathrm{H}$ stretching vibrations of water of crystallization molecules. In this area, we can also observe $\nu(\mathrm{N}-\mathrm{H})$ vibrations of the pyrrole $\mathrm{NH}$ bond at $3320 \mathrm{~cm}^{-1}$. The stretching vibrations of aromatic $\mathrm{C}-\mathrm{H}$ groups of the phenyl rings and pyrrole rings of the $\mathrm{H}_{2}$ TPPS $^{4-}$ ligand were observed around $3100 \mathrm{~cm}^{-1}$, and the stretching vibrations of aromatic $\mathrm{C}=\mathrm{C}$ groups were observed around $1633 \mathrm{~cm}^{-1}$. The tetrapyrrole core was also confirmed by stretching vibration $\nu(\mathrm{C}-\mathrm{N}-\mathrm{C})$ at $1473 \mathrm{~cm}^{-1}$. Asymmetric and symmetric stretching vibrations of $\nu(\mathrm{O}-\mathrm{S}-$ O) were observed at 1164 and $1012 \mathrm{~cm}^{-1}$, respectively. In the wavenumber around $740 \mathrm{~cm}^{-1}$, absorption bands of $\mathrm{C}-\mathrm{S}$ stretching vibrations were observed. Moreover, opening and closing umbrella-shaped vibrations of the $\mathrm{SO}_{3}{ }^{-}$group were confirmed by deformation vibration at $633 \mathrm{~cm}^{-1}$.

In the solid-state UV-VIS spectra of free $\mathrm{H}_{6}$ TPPS acid (see Figure S8 in the Supporting Information), typical absorption bands of the ligand can be observed, including one strong asymmetric Soret band with two contributions (although not fully resolved). The Soret band, corresponding to the $S_{0} \rightarrow S_{2}$ transition, was observed at $\sim 450 \mathrm{~nm}$ and four $\mathrm{Q}$ bands were observed in the area from 500 to $620 \mathrm{~nm}$ (corresponding to the higher vibrational mode $\mathrm{Q}(1,0)$ and the lower energy vibrational mode $Q(0,0)$ of the $S_{0} \rightarrow S_{1}$ transition). The solidstate UV-VIS absorption spectra of UPJS-10 obviously differ from those of free $\mathrm{H}_{6}$ TPPS acid. In the spectrum of UPJS-10, we can observe a bathochromic shift and strong peaks at 454 , 463 , and $482 \mathrm{~nm}$, and two asymmetric $Q$ bands with the highest peak at $589 \mathrm{~nm}$ (see Figure S8a in the Supporting Information). Before singlet oxygen phosphorescence measurements, we also measured the solution-state adsorption spectra in distilled water. The spectrum is shown in Figure S8b in the Supporting Information. The spectra of UPJS-10 in the solution are similar to those observed in the solid state. In the solution, we can observe a double-shaped Soret band with maxima at 415 and $434 \mathrm{~nm}$ and four Q bands in the area from 500 to $650 \mathrm{~nm}$, the strongest one having the maximum at 645 $\mathrm{nm}$. The number of $\mathrm{Q}$ bands found in the solution-state UVVis spectrum indicates the nonmetalation of the center of the macrocyclic porphyrin core, consistent with SXRD results. The wavenumber near the maximum of the $Q$ band $(630 \mathrm{~nm})$ was used to determine the wavenumber of the excitation laser pulses in the singlet oxygen measurements.

The singlet oxygen phosphorescence signal was measured for the compound UPJS-10 suspended in water. After the sample centrifugation (see Characterization) followed by supernatant removal and its replacement with water, the solution was transparent. However, the solution color gradually turned green in a few minutes (see Figure $S 8 b$ in the Supporting Information), which indicates degradation of the compound UPJS-10. Indeed, the presence of free $\mathrm{H}_{6}$ TPPS was confirmed by absorption measurements. The absorption spectra were measured 2 and $15 \mathrm{~min}$ after centrifugation and supernatant replacement (see Figure S8b in the Supporting Information). There is clear evidence of the $\mathrm{Q}$ band in the UV-VIS spectrum with a maximum at $645 \mathrm{~nm}$, and $630 \mathrm{~nm}$ was used in excitation laser pulses (see Figure S8b). The time courses of the singlet oxygen phosphorescence signal measured during the first $12.5 \mathrm{~min}$ (first measurement) and ca. $15 \mathrm{~min}$ later (second measurement) are shown in Figure 3.

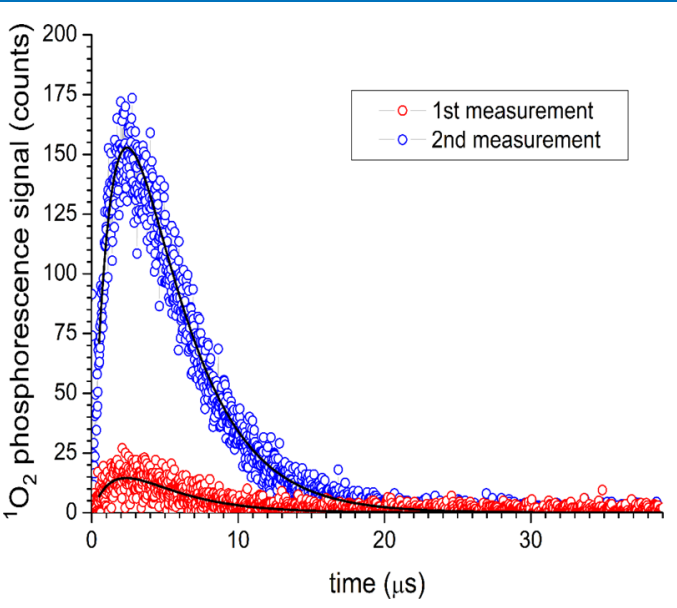

Figure 3. Experimental kinetics of singlet oxygen phosphorescence produced by excitation of UPJS-10 suspended in water at $630 \mathrm{~nm}$. The experimental curves were fitted by eq 1 (solid black lines).

The higher phosphorescence intensity detected in the second measurement suggests that the observed singlet oxygen originated preferentially from the freely dissolved $\mathrm{H}_{6}$ TPPS. This fact might have hindered the observation of possible, however weaker, singlet oxygen phosphorescence produced inside the MOF structures. The measured data were fitted with the following formula: ${ }^{37}$

$$
P(t)=\frac{A \tau_{\Delta}}{\tau_{\Delta}-\tau_{\mathrm{T}}}\left(e^{-\left(t / \tau_{\Delta}\right)}-e^{-\left(t / \tau_{\mathrm{T}}\right)}\right)
$$

where $\tau_{\Delta}$ and $\tau_{\mathrm{T}}$ are the lifetimes of singlet oxygen and triplet state TPPS, respectively. The experimental data were well reproduced by eq 1 , with $\tau_{\Delta}=3.6 \mu \mathrm{s}$ and $\tau_{\mathrm{T}}=1.7 \mu \mathrm{s}$. The present singlet oxygen lifetime is in very good agreement with the value expected for the water environment $\left(\tau_{\Delta}=3.5 \mu \mathrm{s}\right){ }^{38}$ which supports the assumption that the observed singlet oxygen was produced outside the UPJS-10 structure by a dissociated ligand.

Thermal Analysis and Gas Adsorption Properties. Thermal stability and solvent removal during the heating of UPJS-10 and UPJS-12 were studied by thermogravimetric analysis (TGA, see Figure 4), measured in the temperature range of $25-900{ }^{\circ} \mathrm{C}$ under a flow of air $\left(20 \mathrm{~mL} \mathrm{~min}^{-1}\right)$ and a heating ramp rate of $6^{\circ} \mathrm{C} \mathrm{min}-1$. The TG curve of UPJS-10 is depicted in Figure 4a. Thermal analysis shows that after dehydration of UPJS-10, the 3D porous framework is thermally stable up to $400{ }^{\circ} \mathrm{C}$. The first step of the thermal decomposition takes place in the temperature range from 25 to $130{ }^{\circ} \mathrm{C}$ and corresponds to the removal of 11 water of crystallization molecules from the channel system (observed weight loss, 5.5 wt \%; calc., 5.3 wt \%). In the next step, the structure is thermally stable up to $400{ }^{\circ} \mathrm{C}$; above this 


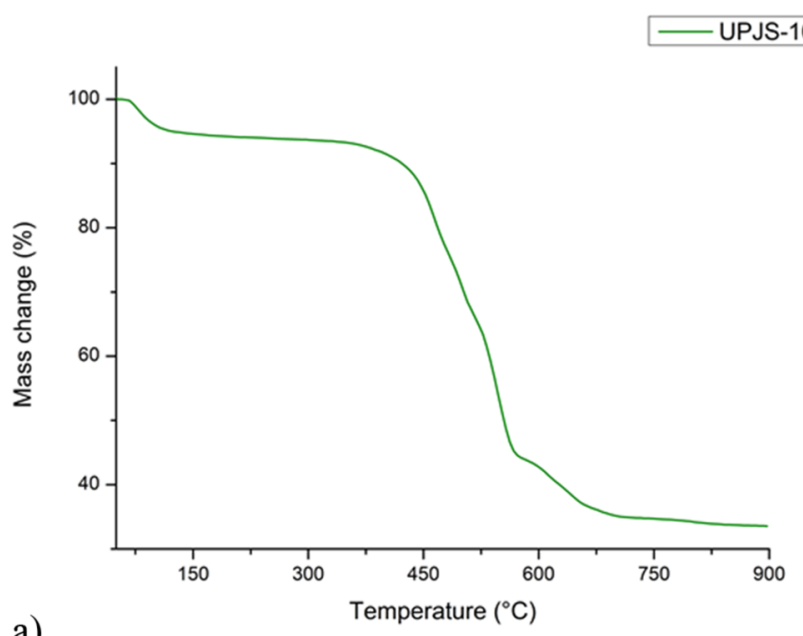

a)

Figure 4. Thermogravimetric curves of (a) UPJS-10 and (b) UPJS-12.

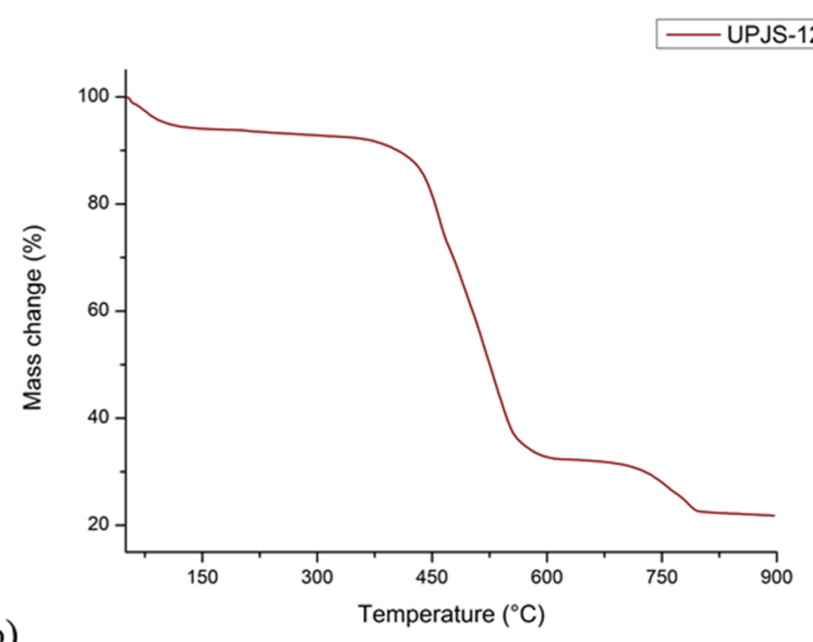

b) temperature, the framework of UPJS-10 collapses, and the decomposition of organic $\mathrm{H}_{2}$ TTPS ${ }^{4-}$ ligand takes place up to $730{ }^{\circ} \mathrm{C}$. The residual solid product represented 33.5 wt \%, corresponding to the mixture of praseodymium oxides. In the TG curve of the compound UPJS-12, we can observe a similar thermal behavior (see Figure $4 \mathrm{~b}$ ). In the first step of thermal decomposition, up to $130{ }^{\circ} \mathrm{C}$, the removal of 11 water of crystallization molecules takes place (observed weight loss, 5.5 wt \%; calc., $5.6 \mathrm{wt} \%)$. The desolvated sample is further stable up to $400{ }^{\circ} \mathrm{C}$, and above this temperature, the organic part of UPJS-12 starts to decompose. The residual mass of the final thermal decomposition product was $20.0 \mathrm{wt} \%$, which corresponds to the creation of $\mathrm{CeO}_{2}$ (calc., 19.3 wt \%).

The thermal analysis results showed that solvent removal from the samples takes place after heating the materials to 130 ${ }^{\circ} \mathrm{C}$. Therefore, to prepare the samples for gas adsorption measurements, desolvation (activation) of the samples was carried out. The activation process was also studied by in situ heating FT-IR spectroscopy under vacuum at room temperature, $50{ }^{\circ} \mathrm{C}, 100{ }^{\circ} \mathrm{C}$, and $150{ }^{\circ} \mathrm{C}$ (for UPJS-10, see Figure S1, and for UPJS-12, see Figure $S 2$ in the Supporting Information). From the spectra, the decrease in the broad band around $3400 \mathrm{~cm}^{-1}$ was observed, which corresponds to $\mathrm{O}-\mathrm{H}$ stretching vibrations of the water of crystalizzation molecules. The other bands in the spectrum did not have changes, which confirms the stability of complexes during the degassing process. The samples were degassed at $150{ }^{\circ} \mathrm{C}$ for 16 $h$ under dynamic vacuum and subjected to adsorption measurements of argon and carbon dioxide, and all adsorption measurements were performed on the same batch of the sample.

Argon adsorption isotherms of compounds UPJS-10 and UPJS-12 can be classified as type I by IUPAC classification (see Figure 5), which is typical for microporous materials. Based on argon adsorption measurements, the BET surface areas $\left(S_{\mathrm{BET}}\right)$ of the activated samples were evaluated using adsorption data in the $p / p_{0}$ range of $0.02-0.1$. The pore volume $\left(V_{\mathrm{p}}\right)$ and pore size diameter of UPJS-10 and UPJS-12 were evaluated using the DFT method (see Figure S9 in the Supporting Information). Evaluation of the argon adsorption data using the BET equation gave the specific surface area values of 259 and $229 \mathrm{~m}^{2} \mathrm{~g}^{-1}$ for UPJS-10 and UPJS-12, respectively. The determined micropore volume $\left(V_{\mathrm{p}}\right)$ and pore

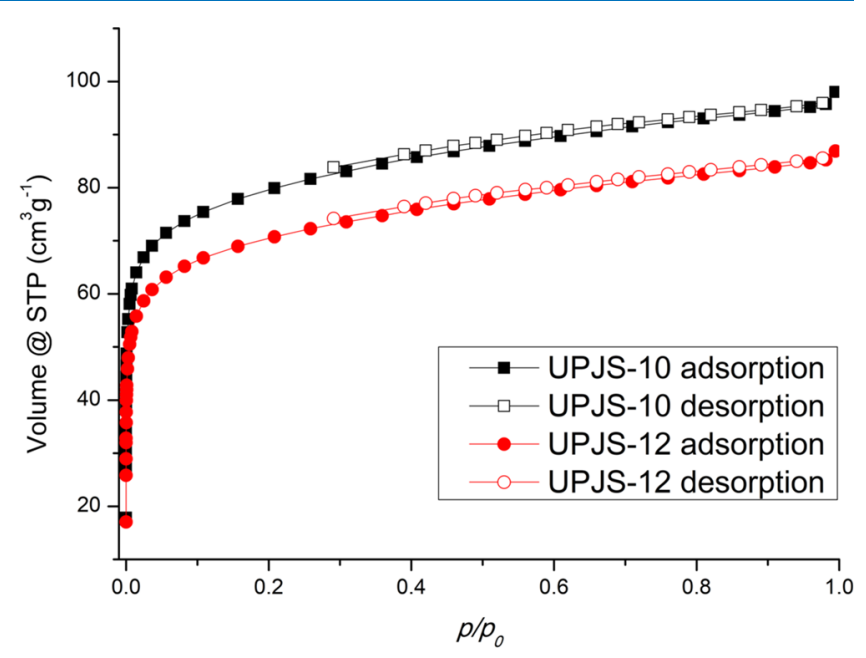

Figure 5. Argon adsorption/desorption isotherms of UPJS-10 (black curve) and UPJS-12 (red curve) measured at $-186^{\circ} \mathrm{C}$.

size diameter for UPJS-10 were $0.121 \mathrm{~cm}^{3} \mathrm{~g}^{-1}$ and $1.88 \mathrm{~nm}$, respectively. The micropore volume and pore size diameter of the sample UPJS-12 were determined as $0.108 \mathrm{~cm}^{3} \mathrm{~g}^{-1}$ and $1.87 \mathrm{~nm}$, respectively. The pore size diameter calculated from the SXRD measurement for UPJS-10 and UPJS-12 is in very good agreement with results from Ar adsorption measurements (1.91 and $1.90 \mathrm{~nm}$ for SXRD and 1.88 and 1.87 for the DFT method, calculated from argon adsorption data).

Carbon dioxide measurements were performed at two temperatures, 0 and $20{ }^{\circ} \mathrm{C}$ (see Figure $6 \mathrm{a}, \mathrm{b}$ ). Carbon dioxide adsorption isotherms at $20{ }^{\circ} \mathrm{C}$ showed that the compound UPJS-10 adsorbed up to 1 bar of $38 \mathrm{~cm}^{3} \mathrm{~g}^{-1} \mathrm{CO}_{2}$, which corresponds to 6.95 wt $\%\left(1.58 \mathrm{mmol} \mathrm{g}^{-1}\right) \mathrm{CO}_{2}$, and the compound UPJS-12 adsorbed up to 1 bar of $33 \mathrm{~cm}^{3} \mathrm{~g}^{-1} \mathrm{CO}_{2}$ corresponding to $5.99 \mathrm{wt} \%\left(1.36 \mathrm{mmol} \mathrm{g}^{-1}\right) \mathrm{CO}_{2}$. The carbon dioxide adsorption measurements at $0{ }^{\circ} \mathrm{C}$ showed that UPJS10 and UPJS-12 adsorbed $50 \mathrm{~cm}^{3} \mathrm{~g}^{-1}$ (corresponding to 9.83 wt $\%, 2.23 \mathrm{mmol} \mathrm{g}^{-1}$ ) and $44 \mathrm{~cm}^{3} \mathrm{~g}^{-1} \mathrm{CO}_{2}$ (corresponding to 8.58 wt $\%, 1.95 \mathrm{mmol} \mathrm{g}^{-1}$ ), respectively. A comparison of observed values of UPJS-10 and UPJS-12 with other MPF materials containing the $\mathrm{H}_{2}$ TPPS $^{4-}$ ligand and inner transition metal elements as the central atom (La(III), Sm(III), and $\mathrm{Eu}(\mathrm{III})$ ions) indicated lower values of adsorbed carbon 

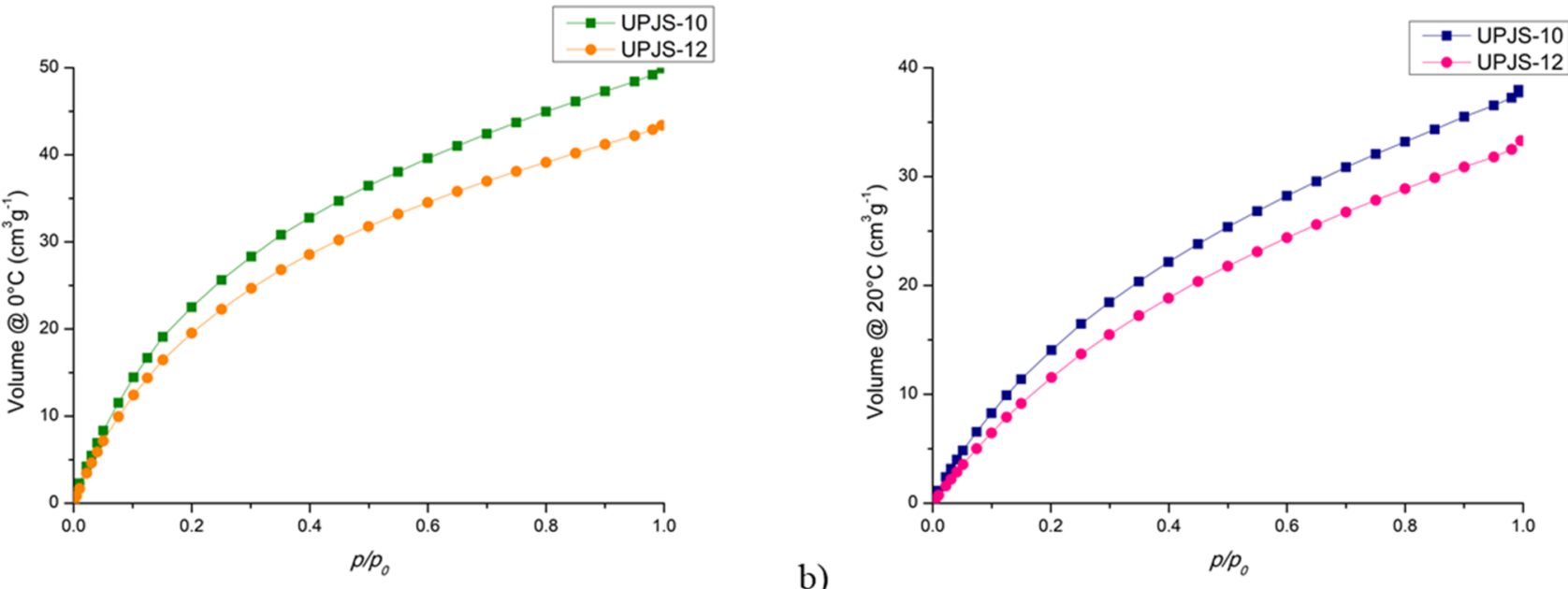

a)

b)

Figure 6. Carbon dioxide adsorption isotherms of UPJS-10 and UPJS-12 measured at (a) $0{ }^{\circ} \mathrm{C}$ and (b) $20{ }^{\circ} \mathrm{C}$.

dioxide at $0{ }^{\circ} \mathrm{C}\left(0.9,1.2\right.$, and $1.9 \mathrm{mmol} \mathrm{g}^{-1}$ for $\mathrm{La}(\mathrm{III}), \mathrm{Eu}(\mathrm{III})$, and $\mathrm{Sm}$ (III) forms, respectively). ${ }^{24,36}$ The observed values for UPJS-10 and UPJS-12 are relatively high and can be attributed to the interactions of carbon dioxide, as an acidic gas, with free electron pairs of basic nitrogen atoms in the $\mathrm{H}_{2} \mathrm{TPPS}^{4-}$ core. Such interactions of carbon dioxide in nitrogen-containing MOFs are well reported. ${ }^{39}$

Magnetic Properties. To investigate the magnetic properties of the prepared MPFs UPJS-10 and UPJS-12, the magnetic susceptibility and EPR spectra were studied in a wide temperature and magnetic field range. In addition, a Labased analogue, $\left[\mathrm{La}\left(\mathrm{H}_{2} \mathrm{TPPS}\right)\right]_{n} \cdot n \mathrm{H}_{5} \mathrm{O}_{2}^{+}$, was synthesized for complex comparison. ${ }^{24}$ The magnetic susceptibility (defined as the ratio of the measured magnetic moment and applied magnetic field of $1 \mathrm{kOe}$ ), recorded in both zero-field-cooled (ZFC) and field-cooled (FC) regimes, was measured, but no irreversibility of the magnetic responses was observed in any of the MPFs. A gradual increase in the molar susceptibility was observed when decreasing the temperature.

The electronic ground state of $4 \mathrm{f}$ ions in the studied MPFs is determined by electron-electron interaction and the spinorbit coupling removing the $(2 J+1)$-fold degeneracy of each multiplet associated with a total angular momentum $J$. The energy levels of the ground-state multiplet are known as Stark levels. They are usually depopulated as temperature decreases from $300 \mathrm{~K}$, leading to the decrease in $\chi T$ as observed in our experiments (see Figure 7 ). The ground-state multiplet of the $\operatorname{Pr}(\mathrm{III})$ ion (electronic configuration $4 \mathrm{f}^{2}$ ) is ${ }^{3} \mathrm{H}_{4}$; thus, this is a non-Kramers ion with $J=4$ and $g$-factor $g_{\mathrm{J}}=4 / 5$. On the other hand, the $\mathrm{Ce}(\mathrm{III})$ ion (electronic configuration $4 \mathrm{f}^{1}$ ) with the ground-state multiplet ${ }^{2} F_{5 / 2}$ is a Kramers ion with $J=5 / 2$ and $g$-factor $g_{\mathrm{J}}=6 / 7$. Obviously, the $\mathrm{La}(\mathrm{III})$ ion $\left(4 \mathrm{f}^{0}\right)$ is nonmagnetic.

The observed room-temperature experimental value of $\chi T$ of UPJS-12 is close to the theoretical prediction of $0.805 \mathrm{~cm}^{3} \mathrm{~K} /$ mol for a free $\mathrm{Ce}$ (III) ion and then gradually decreases by lowering the temperature to $0.352 \mathrm{~cm}^{3} \mathrm{~K} / \mathrm{mol}$. This value is very close to the one corresponding to a well-isolated ground Kramers doublet that could be described by the effective spin $S_{\text {eff }}=1 / 2$. Similar to other cerrous magnets, the separation between the ground and first excited Kramers doublets is expected to be higher than $200\left(140 \mathrm{~cm}^{-1}\right),{ }^{40-43}$ but some extreme values were also reported. ${ }^{44}$ In the temperature range

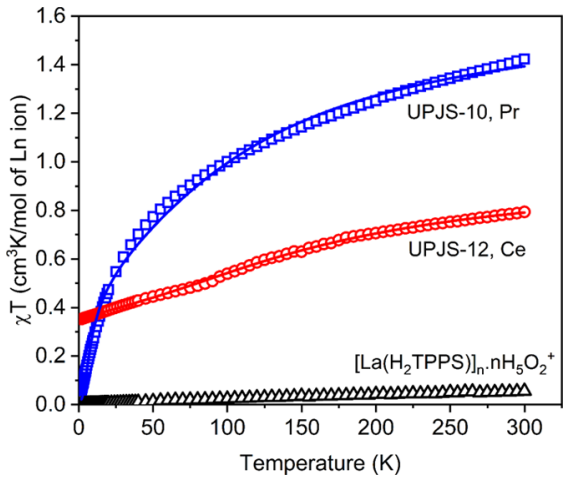

Figure 7. Temperature dependence of the $\chi T$ product of UPJS-10, UPJS-12, and $\left[\mathrm{La}\left(\mathrm{H}_{2} \mathrm{TPPS}\right)\right]_{n} \cdot n \mathrm{H}_{5} \mathrm{O}_{2}{ }^{+}$(open symbols). The solid red line represents the fit of the simplified Van Vleck model using eq 2 for UPJS-12, and the solid blue line represents the fit of the crystal-field Hamiltonian in the Stevens notation for UPJS-10.

of up to $300 \mathrm{~K}$, where only the populations of the ground and first excited doublets are significant, one can use a simplified expression derived using Van Vleck's general formalism for the susceptibility of anisotropic spins ${ }^{45-47}$

$$
\begin{aligned}
\chi T= & \left(\frac{N_{\mathrm{A}} \mu_{\mathrm{B}}^{2}}{4 k_{\mathrm{B}}}\right)\left[C_{0}+C_{1}\left(\frac{2 k_{\mathrm{B}} T}{\Delta}\right) \tanh \left(\frac{\Delta}{2 k_{\mathrm{B}} T}\right)\right. \\
& \left.+C_{2} \tanh \left(\frac{\Delta}{2 k_{\mathrm{B}} T}\right)\right]
\end{aligned}
$$

with $N_{\mathrm{A}}$ as the Avogadro constant, $k_{\mathrm{B}}$ as the Boltzmann constant, and $\mu_{\mathrm{B}}$ as the Bohr magneton. The parameter $\Delta$ is the energy gap between the ground and first excited doublets, and parameters $C_{0}, C_{1}$, and $C_{2}$ are related to the electronic structure of both doublets, e.g., to their $g$-tensor. The best fit of eq 2 to our experimental data of UPJS-12 as shown in Figure 7 yielded the energy gap $\Delta / k_{\mathrm{B}}=321 \mathrm{~K}\left(223 \mathrm{~cm}^{-1}\right)$ with parameters $C_{0}=7.52, C_{1}=3.03$, and $C_{2}=-3.76$. The obtained energy gap is very close to the one obtained for cerrous complexes. $^{40}$

The ground doublet is well separated, and this is manifested by the field dependence of the magnetization at $1.8 \mathrm{~K}$ (Figure 8) that displays Brillouin-like behavior for an effective spin $S_{\text {eff }}$ $=1 / 2$. The magnetization value of $0.82 N_{\mathrm{A}} \mu_{\mathrm{B}}$ at $70 \mathrm{kOe}$ 


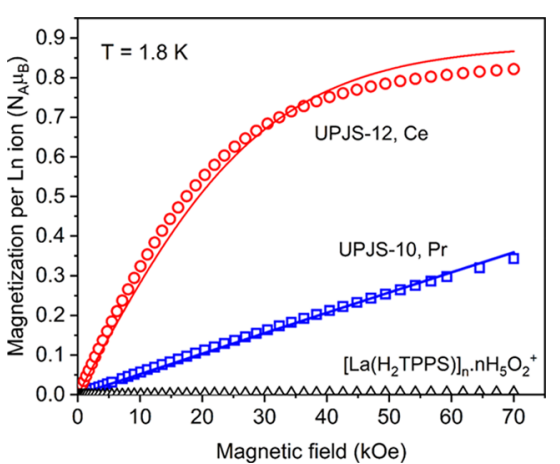

Figure 8. Field dependence of the magnetization of UPJS-10, UPJS12 , and $\left[\mathrm{La}\left(\mathrm{H}_{2} \mathrm{TPPS}\right)\right]_{n} \cdot n \mathrm{H}_{5} \mathrm{O}_{2}{ }^{+}$measured at $1.8 \mathrm{~K}$. The solid red line represents the simulation of the Brillouin function with the effective spin $S_{\text {eff }}=1 / 2$ for UPJS-12, and the solid blue line represents the fit of the crystal-field Hamiltonian in the Stevens notation for UPJS-10.

corresponds to an average effective $g$-factor of the ground doublet of about 1.65. No significant reduction of $\chi T$ at the lowest temperatures was observed that rules out a significant influence of the exchange interaction, which is typically very low between lanthanide ions as shown for dimeric lanthanide complexes with a much shorter exchange path through a double oxygen bridge; ${ }^{41,48-51}$ some exceptions are examples of Dy(III)-based molecular magnets summarized in ref 52 .

To obtain more insight into the low-temperature properties of UPJS-12, we have performed X-band EPR measurements shown in Figure 9. The intensity of the EPR spectra decreases

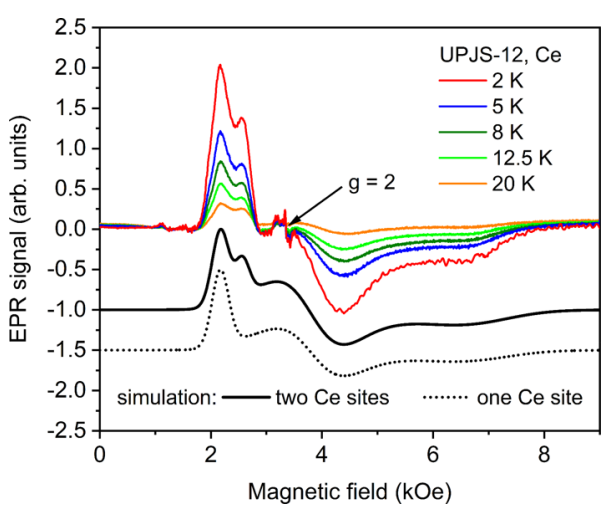

Figure 9. X-band EPR spectra of UPJS-12 measured in the temperature range of $2-20 \mathrm{~K}$. The dotted black line represents the simulation, including one $\mathrm{Ce}$ (III) site, while the solid black line includes two $\mathrm{Ce}(\mathrm{III})$ sites with slightly different $g$-tensor anisotropy using an effective spin $S_{\text {eff }}=1 / 2$ model within the EasySpin simulation package.

with increasing temperature from 2 to $20 \mathrm{~K}$, suggesting paramagnetic-like behavior. The spectra were analyzed using an effective spin $S_{\text {eff }}=1 / 2$ model, given that the ground doublet is well separated from the excited ones, within the EasySpin simulation package ${ }^{53}$ to obtain the $g$-tensor components of the only populated ground Kramers doublet. First, only one set of $g_{x}=0.99, g_{y}=1.73$, and $g_{z}=3.04$ was obtained, assuming only one $\mathrm{Ce}(\mathrm{III})$ site (the dotted line in Figure 9). The splitting of the low-field component of the spectra between 2 and $3 \mathrm{kOe}$ cannot be explained, e.g., in the presence of the hyperfine interaction due to the lack of nonzero nuclear spin isotopes of cerium atoms. Two inequivalent $\mathrm{Ce}$ (III) sites need to be included in the simulation with different $g_{z}$ components to describe the experimental spectra satisfactorily. The best agreement was obtained for $g_{z 1}$ $=3.04$ and $g_{z 2}=2.57$ with the occupation ratio of $3: 1$, while the $g_{x}=0.99$ and $g_{y}=1.73$ are the same for both sites. The two inequivalent $\mathrm{Ce}$ (III) sites could be present due to the structural disorder in the MPF structure. The disorder could lead to two slightly different coordination oxygen polyhedra of the $\mathrm{Ce}$ (III) ions affecting the crystal field environment. For the comparison, the average $g$-factor of about 2.04 obtained from EPR data assuming the 3:1 site population yields slightly higher low-temperature $\chi T$ values as observed from the magnetic data. Interestingly, the $g$-tensor components are similar to those also observed in Ce(III)-containing heterodinuclear complexes proposed as potential molecular spin quantum gates. ${ }^{41}$ In addition to the $\mathrm{Ce}(\mathrm{III})$ signal, a narrow component of the EPR spectra with $g=2$ was observed. Strong signal saturation depending on incident microwave power suggests the lack of an orbital angular momentum of the active species. A possible origin of this signal was tentatively assigned to the radical spins occupying the $\mathrm{H}_{2} \mathrm{TPPS}^{-4}$ ligands, vide infra.

For UPJS-10, the temperature dependence of the $\chi T$ is significantly reduced from the room-temperature value of 1.42 $\mathrm{cm}^{3} \mathrm{~K} / \mathrm{mol}$, which is lower than the expected $1.6 \mathrm{~cm}^{3} \mathrm{~K} / \mathrm{mol}$ and reaching only $0.05 \mathrm{~cm}^{3} \mathrm{~K} / \mathrm{mol}$ at $2 \mathrm{~K}$, as shown in Figure 8. The lower room-temperature value of $\chi T$ could be the result of several effects. We may speculate about the presence of a partial change in the valence from $\operatorname{Pr}(\mathrm{III})$ to $\operatorname{Pr}(\mathrm{IV})$ with $4 \mathrm{f}^{1}$ electronic configuration similar to a $\mathrm{Ce}$ (III) ion, which is a Kramers ion. The electron transfer between praseodymium and the porphyrin ligand may lead to the creation of radical spins, similar to UPJS-12. An electron transfer-induced change in the electronic structure was observed in $\mathrm{Fe}$-porphyrin complexes; ${ }^{54}$ nevertheless, the metal center was coordinated at the central part of the porphyrin ligand in contrast with UPJS10 and UPJS-12. Different radical species were also observed in various porphyrin modifications ${ }^{55}$ by the time-resolved EPR or were predicted theoretically. ${ }^{56}$ On the other hand, similar values of room-temperature $\chi T$ and the overall temperature dependence of $\chi T$ were observed in well-isolated mononuclear $\operatorname{Pr}(\mathrm{III})$ complexes as reported, e.g., in ref 57. The lack of evidence of strong exchange interaction in the $\mathrm{Ce}$ (III) analog UPJS-12 strongly suggests that a model of non-interacting $\operatorname{Pr}(\mathrm{III})$ ions is appropriate due to the similarity between the structures of UPJS-10 and UPJS-12. A substantial reduction of $\chi T$ at low temperatures then can result from the depopulation of Stark levels with a high total angular momentum quantum number $m_{\mathrm{J}}$. The ground state of non-Kramers $\operatorname{Pr}(\mathrm{III})$ in the presence of low-symmetry components of the crystal field can be a nondegenerate singlet or a quasi-doublet of two closelying levels as in $\mathrm{CsPr}\left(\mathrm{MoO}_{4}\right)_{2}$ with a ground quasi-doublet with an energy separation of $14 \mathrm{~cm}^{-1}(\sim 20 \mathrm{~K})$. $^{58}$

A linear field dependence of magnetization and its small value of $0.34 N_{\mathrm{A}} \mu_{\mathrm{B}}$ at $70 \mathrm{kOe}$ and $1.8 \mathrm{~K}$ for UPJS-10 (see Figure 8) can be explained by a similar energy-level separation with ground-state level $m_{\mathrm{J}}=0$. A preliminary report about the magnetic properties of UPJS-10 ${ }^{59}$ did not allow one to perform a detailed analysis due to the lacking details about its structure. Also, a model (eq 1) used for the description of UPJS-12 is not suitable for estimating the crystal-field parameters of $\operatorname{Pr}(\mathrm{III})$ ions in UPJS-10 with such a small energy separation. In this work, a more complex Hamiltonian, which includes the influence of spin-orbit coupling and 
crystal-field effects using the operator equivalent technique of Stevens and Bleaney ${ }^{6,61}$ as implemented in the software package $\mathrm{PHI}{ }^{62}$ was employed to analyze the magnetic response of UPJS-10. The local crystal-field symmetry of $\operatorname{Pr}(\mathrm{III})$ in studied MPF is $D_{4 d}$ and the crystal-field parameters $B_{2}^{0}, B_{4}^{0}$, and $B_{6}^{0}$ in the Stevens notation are necessary for the proper description of magnetic properties. ${ }^{52}$ The best agreement with the experimental data as shown in Figures 7 and 8 was obtained with $B_{2}^{0}=-1632.5 \mathrm{~cm}^{-1}(-2350.8 \mathrm{~K}), B_{4}^{0}=$ $-550.1 \mathrm{~cm}^{-1}(-1558.6 \mathrm{~K})$, and $B_{6}^{0}=-190.5 \mathrm{~cm}^{-1}(-274.3 \mathrm{~K})$. This set of parameters is better understood by looking at the energies of resulting Stark levels and the composition of the wave functions of the resulting microstates. The ground state of UPJS-10 is a singlet separated from the first excited doublet by the energy of $10 \mathrm{~cm}^{-1}(14.4 \mathrm{~K})$. The ground state in the notation of spin and orbital quantum numbers $\left|m_{S}, m_{L}\right\rangle$ is composed of $48 \%$ of $|0,0\rangle$ and $52 \%$ of $| \pm 1, \pm 1\rangle$ states. In the simplified total angular momentum notation, $\left|J, m_{J}\right\rangle$, the ground state is composed of $99.95 \%$ of the $|4,0\rangle$ state and the first excited doublet is composed of $99.3 \%$ of the $|4, \pm 3\rangle$ state, which explains the drop of the $\chi T$ to almost zero value and the magnetization behavior at low temperatures. The low-temperature magnetic properties are likely not affected by the next excited doublet $|4, \pm 1\rangle$ with an energy of $175 \mathrm{~cm}^{-1}(252 \mathrm{~K})$. Further small deformations of local symmetry at the $\operatorname{Pr}(\mathrm{III})$ site (with additional crystal-field parameters in Stevens Hamiltonian) may lead to the splitting of excited doublets, which may not be evidenced from magnetic measurements on powdered samples. While for the set of the parameters obtained from the fit of the magnetic response, no EPR transitions are predicted in our experimental range, a further symmetry lowering at the $\operatorname{Pr}(\mathrm{III})$ site might lead to the observation of EPR transitions. The results of the multifrequency EPR study of $\mathrm{CsPr}\left(\mathrm{MoO}_{4}\right)_{2}$ by Kobets et al. ${ }^{58}$ show that the EPR transition may be allowed in the low-temperature X-band EPR experiments. This might be relevant for UPJS-10 as well since a weak signal with $g=6.06$ was observed in our experiments, as shown in Figure 10. No evidence of $\mathrm{Ce}(\mathrm{III})$ -

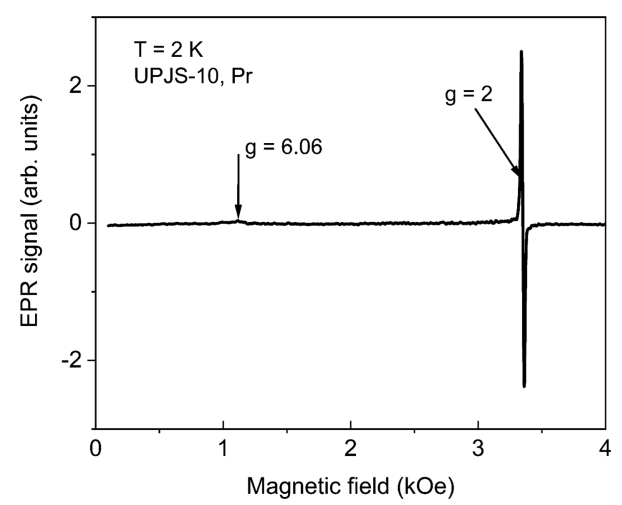

Figure 10. X-band EPR spectra of UPJS-10 measured at $2 \mathrm{~K}$.

like spectra was observed that would suggest a significant presence of $\operatorname{Pr}(\mathrm{IV})$ ions in UPJS-10. On the other hand, the Xband EPR spectra of UPJS-10 are dominated by a sharp $g=2$ resonance (Figure 10), which is present in the whole temperature range between 2 and $300 \mathrm{~K}$ with paramagneticlike behavior, i.e., the signal intensity decreases with increasing temperature.
Some additional experiments were performed on [La$\left(\mathrm{H}_{2}\right.$ TPPS $\left.)\right]_{n} \cdot n \mathrm{H}_{5} \mathrm{O}_{2}^{+}$MPF and pure $\mathrm{H}_{6}$ TPPS and $\mathrm{H}_{6}$ TPPS. $n \mathrm{H}_{2} \mathrm{O}$ samples to assign the $g=2$ signal to radical species related to porphyrin ligands. First, we briefly mention the magnetic response of $\left[\mathrm{La}\left(\mathrm{H}_{2} \mathrm{TPPS}\right)\right]_{n} \cdot n \mathrm{H}_{5} \mathrm{O}_{2}{ }^{+}$shown in Figures 7 and 8 . The $\chi \mathrm{T}$ product of $[\mathrm{La}(\mathrm{TPPS})]_{n} \cdot \mathrm{nH}_{5} \mathrm{O}_{2}$ reaches only $0.05 \mathrm{~cm}^{3} \mathrm{~K} / \mathrm{mol}$ at room temperature, and lowtemperature magnetization shows Brillouin-like behavior with $0.01 N_{\mathrm{A}} \mu_{\mathrm{B}}$ at $70 \mathrm{kOe}$ and $1.8 \mathrm{~K}$. This magnetic contribution may be a result of a small portion of paramagnetic impurities or radical spins, e.g., up to 0.1 of the $S=1 / 2$ spins per unit formula. Further EPR experiments confirmed the $g=2$ signal in all $\left[\mathrm{La}\left(\mathrm{H}_{2} \text { TPPS }\right)\right]_{n} \cdot n \mathrm{H}_{5} \mathrm{O}_{2}{ }^{+}, \mathrm{H}_{6}$ TPPS, and $\mathrm{H}_{6}$ TPPS $\cdot n \mathrm{H}_{2} \mathrm{O}$ complexes. In detail, the low-temperature EPR spectra collected using the rapid-scan mode as implemented in a Bruker ELEXSYS II E-500 spectrometer are shown in Figure 11.

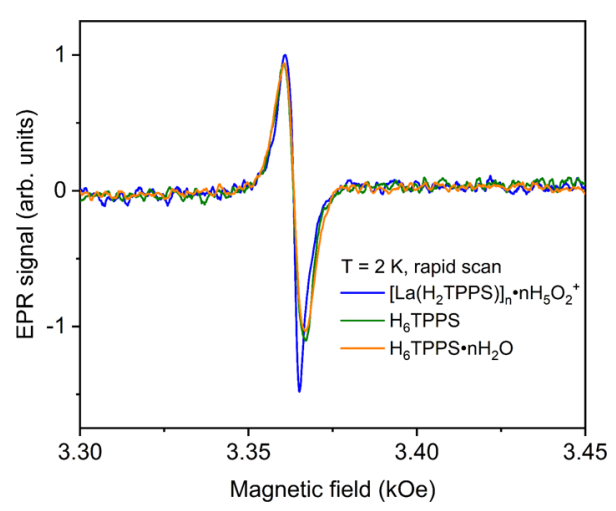

Figure 11. X-band EPR spectra of different complexes under study collected in rapid-scan mode at $2 \mathrm{~K}$. Experiment parameters: microwave power, $0.6325 \mu \mathrm{W}$; number of points, 2048; number of scans, 2000; repetition rate, $39.16 \mathrm{~Hz}$; modulation amplitude, 1 Oe.

The rapid-scan experiments were performed with a low incident microwave power of $0.6325 \mu \mathrm{W}$ to avoid distortion of the EPR signal due to the strong saturation effects. The presence of the $g=2$ signal with a peak-to-peak linewidth of 5-7 Oe in all studied samples suggests that it originates from the porphyrin-based radical spin also in UPJS-10 and UPJS12. In the future, it would be possible to get more information on the radical spins in studied MPFs using the time-resolved EPR and NMR experiments as in refs 56 and 58. Also, the detailed prediction of the crystal field-field parameters of $\operatorname{Pr}(\mathrm{III})$ and $\mathrm{Ce}$ (III) ions in UPJS-10 and UPJS-12, respectively, using $a b$ initio calculations, would shed light on the details of the electronic structure of both ions and observed features in the EPR spectra.

\section{CONCLUSIONS}

Novel porous coordination polymers with the formulas $\left\{\left[\mathrm{Pr}_{4}\left(\mathrm{H}_{2} \mathrm{TPPS}\right)_{3}\right] \cdot 11 \mathrm{H}_{2} \mathrm{O}\right\}_{n}$ (UPJS-10), $\left\{\left[\mathrm{Eu} / \mathrm{Sm}\left(\mathrm{H}_{2} \mathrm{TPPS}\right)\right]\right.$. $\left.\mathrm{H}_{3} \mathrm{O}^{+} \cdot 16 \mathrm{H}_{2} \mathrm{O}\right\}_{n}$ (UPJS-11), and $\left\{\left[\mathrm{Ce}_{4}\left(\mathrm{H}_{2} \text { TPPS }\right)_{3}\right] \cdot 11 \mathrm{H}_{2} \mathrm{O}\right\}_{n}$ (UPJS-12), were prepared and investigated. The structure of the complexes can be described as a $3 \mathrm{D}$ open porous framework. Three mutually crossing cavities are present in the structure of the complexes with sizes of approximately $5 \times$ $5.5 \AA^{2}$ (along $a$ and $b$ crystallographic axes) and $8 \times 8.3 \AA^{2}$ (along the $c$ crystallographic axis). Gas adsorption measurements showed that the frameworks of UPJS-10 and UPJS-12 
are accessible for carbon dioxide molecules, and complexes adsorbed 2.23 and $1.95 \mathrm{mmol} \mathrm{g}^{-1} \mathrm{CO}_{2}$ at $0{ }^{\circ} \mathrm{C}$, respectively. UPJS-10 and UPJS-12 adsorb the highest amount of carbon dioxide among the groups of MPF compounds. The magnetic properties of UPJS-12 are governed by the presence of two Kramers doublets of $\mathrm{Ce}$ (III) ions separated by a significant energy difference of $321 \mathrm{~K}$. On the other hand, $\operatorname{Pr}(\mathrm{III})$ ions in UPJS-10 are characterized by a small energy difference of 14.4 $\mathrm{K}$ between a nonmagnetic ground state singlet and the first excited doublet. The investigation of the X-band EPR spectra also revealed the presence of radical spins, which were tentatively assigned to be originating from the porphyrin ligands.

\section{EXPERIMENTAL SECTION}

Materials. All chemicals used in the synthesis and applications of prepared materials were obtained from SigmaAldrich or PorphyChem companies and used without further purification.

Synthesis. Synthesis of $\left\{\left[\mathrm{Pr}_{4}\left(\mathrm{H}_{2} \text { TPPS }\right)_{3}\right] \cdot 11 \mathrm{H}_{2} \mathrm{O}\right\}_{n}$ (UPJS10). Dark green needles of the compound UPJS-10 were prepared by hydrothermal synthesis. A mixture of $\operatorname{Pr}\left(\mathrm{NO}_{3}\right)_{3}$. $6 \mathrm{H}_{2} \mathrm{O}$ (23.26 mg, $0.05 \mathrm{mmol}$ ), $\mathrm{H}_{6}$ TPPS ( $50 \mathrm{mg}, 0.05 \mathrm{mmol}$ ), and $15 \mathrm{~mL}$ of distilled water was sealed into a $45 \mathrm{~mL}$ Teflonlined stainless steel autoclave, heated to $200{ }^{\circ} \mathrm{C}$ with a heating rate of $10{ }^{\circ} \mathrm{C} \mathrm{min}{ }^{-1}$, and kept at this temperature for 8 days. After this time, the autoclave was cooled down to ambient temperature with a cooling rate of $5{ }^{\circ} \mathrm{C} \mathrm{min}{ }^{-1}$. The obtained crystals of UPJS-10 were filtered off, washed three times with distilled water, and dried (30.5 mg yield, corresponding to $18 \%$ based on $\mathrm{H}_{6}$ TPPS). Elemental analysis for UPJS-10 $\left(\left\{\left[\mathrm{Pr}_{4}\left(\mathrm{H}_{2} \mathrm{TPPS}\right)_{3}\right] \cdot 11 \mathrm{H}_{2} \mathrm{O}\right\}_{n}, \mathrm{C}_{132} \mathrm{H}_{100} \mathrm{~N}_{12} \mathrm{O}_{47} \mathrm{~S}_{12} \mathrm{Pr}_{4} ; M_{\mathrm{w}}=\right.$ $\left.3554.48 \mathrm{~g} \mathrm{~mol}^{-1}\right)$ : calculated $\mathrm{C}, 44.60 \% ; \mathrm{H}, 2.84 \% ; \mathrm{N}$, 4.73\%; S, 10.82\%. Found C, 44.46\%; H, 2.89\%; N, 4.31\%; S, $10.09 \%$. IR (KBr): $\nu, \mathrm{cm}^{-1}: 3414(\mathrm{~s}), 3100(\mathrm{~m}), 1633(\mathrm{w})$, 1473 (m), 1394 (w), 1251 (s), 1164 (s), 1122 (vs), 1046 (vs), 1012(s), $745(\mathrm{~m}), 741(\mathrm{~s})$, and $633(\mathrm{~s})$ (s, strong; m, medium; w, weak).

Synthesis of $\left\{\left[\mathrm{EU} / \mathrm{Sm}\left(\mathrm{H}_{2} \text { TPPS }\right)\right] \cdot \mathrm{H}_{3} \mathrm{O}^{+} \cdot 16 \mathrm{H}_{2} \mathrm{O}\right\}_{n}$ (UPJS-11). Dark brown needles of the compound UPJS-11 were prepared by hydrothermal synthesis according to the following synthetic procedure. A mixture of $\mathrm{Eu}\left(\mathrm{NO}_{3}\right)_{3} \cdot 6 \mathrm{H}_{2} \mathrm{O}$ (4.6 mg, 0.01 $\mathrm{mmol}), \mathrm{Sm}\left(\mathrm{NO}_{3}\right)_{3} \cdot 6 \mathrm{H}_{2} \mathrm{O}(4.75 \mathrm{mg}, 0.01 \mathrm{mmol}), \mathrm{H}_{6} \mathrm{TPPS}(10$ $\mathrm{mg}, 0.01 \mathrm{mmol})$, and $15 \mathrm{~mL}$ of distilled water was kept in a 45 $\mathrm{mL}$ Teflon-lined stainless steel autoclave and heated to $200{ }^{\circ} \mathrm{C}$ with a heating rate of $10^{\circ} \mathrm{C} \mathrm{min}{ }^{-1}$. The reaction mixture was kept isothermally at $200{ }^{\circ} \mathrm{C}$ for 8 days and subsequently cooled down to ambient temperature with a cooling rate of $5{ }^{\circ} \mathrm{C}$ $\mathrm{min}^{-1}$. The crystals of UPJS-11 were filtered off, washed three times with distilled water, and dried in the stream of air $(5 \mathrm{mg}$ yield, corresponding to $42 \%$ based on $\mathrm{H}_{6}$ TPPS). Elemental analysis for UPJS-11 ( $\left\{\left[\mathrm{Eu} / \mathrm{Sm}\left(\mathrm{H}_{2} \text { TPPS }\right)\right] \cdot \mathrm{H}_{3} \mathrm{O}^{+} \cdot 16 \mathrm{H}_{2} \mathrm{O}\right\}_{n}$, $\left.\mathrm{C}_{44} \mathrm{H}_{61} \mathrm{~N}_{4} \mathrm{O}_{29} \mathrm{~S} 4 \mathrm{Eu} / \mathrm{Sm} ; M_{\mathrm{w}}=1390.19 \mathrm{~g} \mathrm{~mol}^{-1}\right)$ : calculated C, $38.01 \%$; H, 4.42\%; N, 4.03\%; S, 9.23\%. Found C, 38.16\%; H, 4.21\%; N, 4.10\%; S, 8.49\%. IR (KBr): $\nu, \mathrm{cm}^{-1}: 3450$ (s), 3103 (m), 1613 (w), 1475 (m), 1394 (w), 1259 (s), 1160 (s), 1121 (vs), 1043 (vs), 1012 (s), 740 (s), and 633 (s).

Synthesis of $\left\{\left[\mathrm{Ce}_{4}\left(\mathrm{H}_{2} \text { TPPS }\right)_{3}\right] \cdot 11 \mathrm{H}_{2} \mathrm{O}\right\}_{n}$ (UPJS-12). Canyon brown needles of the compound UPJS-12 were prepared by hydrothermal synthesis according to the following procedure. A mixture of $\mathrm{Ce}\left(\mathrm{SO}_{4}\right)_{2}(43 \mathrm{mg}, 0.33 \mathrm{mmol}), \mathrm{H}_{6} \mathrm{TPPS}(15 \mathrm{mg}$, $0.05 \mathrm{mmol}$ ), and $15 \mathrm{~mL}$ of distilled water were sealed into a 45 $\mathrm{mL}$ Teflon-lined stainless steel autoclave and heated at $200{ }^{\circ} \mathrm{C}$ (heating ramp of $10{ }^{\circ} \mathrm{C} \mathrm{min}^{-1}$ ) for 8 days. Subsequently, the autoclave was cooled down to ambient temperature with a cooling rate of $5{ }^{\circ} \mathrm{C} \mathrm{min}^{-1}$. The crystals were filtered off, washed three times with distilled water, and dried $(15 \mathrm{mg}$ yield, corresponding to $26.3 \%$ based on $\mathrm{H}_{6}$ TPPS). Elemental analysis for UPJS-12 (\{[ $\left.\left.\mathrm{Ce}_{4}\left(\mathrm{H}_{2} \mathrm{TPPS}\right)_{3}\right] \cdot 11 \mathrm{H}_{2} \mathrm{O}\right\}_{n}$, $\left.\mathrm{C}_{132} \mathrm{H}_{100} \mathrm{~N}_{12} \mathrm{O}_{47} \mathrm{~S}_{12} \mathrm{Ce}_{4} ; M_{\mathrm{w}}=3551.33 \mathrm{~g} \mathrm{~mol}^{-1}\right)$ : calculated C, 44.64\%; H, 2.84\%; N, 4.73\%; S, 10.83\%. Found C, 45.06\%; H, 2.65\%; N, 4.98\%; S, 10.62\%. IR (KBr): $\nu, \mathrm{cm}^{-1}: 3356$ (s), $3106(\mathrm{~m}), 1600(\mathrm{w}), 1487(\mathrm{w}), 1394(\mathrm{w}), 1265$ (s), 1158 (s), 1119 (vs), 1040 (vs), 1012 (s), 741 (s), and 633 (s).

Characterization. The FT-IR spectra of the prepared materials were measured and recorded at laboratory temperature with a Nicolet Avatar FT-IR 6700 spectrometer in the wavenumber range of $4000-400 \mathrm{~cm}^{-1}$. Transmission FT-IR measurements were performed using the $\mathrm{KBr}$ technique. Before the measurements, $\mathrm{KBr}$ was dried in the oven at 500 ${ }^{\circ} \mathrm{C}$ for $4 \mathrm{~h}$ and cooled in a desiccator. The $\mathrm{KBr}$ pellet contained a sample: $\mathrm{KBr}$ mass ratio of 1:100. The diffuse reflectance infrared Fourier transform (DRIFT) measurements were performed at the same instrument, equipped with an electromagnetic source in the mid-infrared region (4000$500 \mathrm{~cm}^{-1}$ ) and a DTGS detector. For each spectrum, 200 scans were accumulated with a resolution of $4 \mathrm{~cm}^{-1}$. IR measurements were performed by the Praying Mantis in situ cell under vacuum and pure $\mathrm{KBr}$ was measured as a reference background.

The elemental analysis was performed using a CHNOS Elemental Analyzer vario MICRO from Elementar Analysensysteme $\mathrm{GmbH}$.

The thermal behavior was studied by thermogravimetric analysis (TGA) in the temperature range of $25-900{ }^{\circ} \mathrm{C}$, with a heating rate of $6{ }^{\circ} \mathrm{C} \mathrm{min}-1$ in the air atmosphere using a STA Netzsch 409PC instrument.

The specific surface area and pore volume of the prepared samples were measured by argon adsorption at $-186{ }^{\circ} \mathrm{C}$ using a Quantachrome AUTOSORB-1-MP automated gas sorption system. Prior to the measurements, the samples were degassed in a vacuum at $150{ }^{\circ} \mathrm{C}$ for $16 \mathrm{~h}$. The total surface area was calculated via the Brunauer-Emmett-Teller (BET) equation and the micropore volume was obtained by means of the DFT method. Adsorption isotherms of carbon dioxide at 0 and 20 ${ }^{\circ} \mathrm{C}$ were measured using a Quantachrome AUTOSORB-iQ-C with a combined volumetric and dynamic sorption system. Before measurements, samples were degassed at $150{ }^{\circ} \mathrm{C}$ for 16 $h$ under dynamic vacuum.

The solid-state UV-VIS spectroscopy measurements were performed in the reflectance mode on a Specord 250 (AnalyticJena) spectrophotometer in the wavelength range of 350-800 nm. The UV-VIS spectra in the liquid phase were measured in absorption mode using the same equipment.

Magnetic properties were investigated using a SQUID (Superconducting Quantum Interference Device) magnetometer MPMS3 in the temperature range of $1.8-300 \mathrm{~K}$ and external dc fields of up to $70 \mathrm{kOe}$. A powder sample was placed in a polypropylene VSM capsule to avoid the contribution of the sample holder. The diamagnetic contribution was estimated using the reported values of $\mathrm{H}_{2}$ TPPS $^{4-}$ and Pascal's constants and subtracted from the total susceptibility. ${ }^{63}$

The X-band EPR measurements were conducted using a Bruker ELEXSYS II E500 spectrometer with the operating frequency of $9.4 \mathrm{GHz}$ equipped with an ESR910 flow-type cryostat. The measurements were performed in the temper- 
ature range from 2 to $300 \mathrm{~K}$. The sample in the form of powder was mixed with Apiezon $\mathrm{N}$ grease and attached to the Suprasil sample holder.

For singlet oxygen phosphorescence detection, the experimental apparatus described in detail elsewhere was used. ${ }^{64}$ Briefly, the samples were excited by 5-7 ns-long laser pulses from an Nd:YAG OPO system operated at $10 \mathrm{~Hz}$ (tuned to $630 \mathrm{~nm})$. The sample $(1.2 \mathrm{~mL})$ was placed in a $10 \times 10 \times 40$ $\mathrm{mm}^{3}$ quartz cuvette equipped with an overhead-type glass stirrer and was kept at room temperature. The average laser power on the sample was $0.5 \mathrm{~mW}$. The time course of the 1270 $\mathrm{nm}$ phosphorescence signal was detected by a photomultiplier tube (H10330A-75, Hamamatsu Photonics K.K., Japan) operated in photon counting mode and connected to a multichannel scaler PCI card (MSA-300, Becker\&Hickl $\mathrm{GmbH}$, Germany). The suspension of the sample for singlet oxygen phosphorescence measurements was prepared by adding $1.26 \mathrm{mg}$ of powdered compound UPJS-10 in $1.2 \mathrm{~mL}$ of distilled water. So, the prepared suspension was further fragmentized by ultrasonic agitation. The sample color gradually turned green, suggesting degradation of the MOF structures and dissociation of $\mathrm{H}_{6}$ TPPS (see FT-IR and UVVIS Spectral Study and Reactive Oxygen Scavenging). The solution was centrifuged at 10,000 RPM; the supernatant was removed and replaced by a new solvent to remove the free $\mathrm{H}_{6}$ TPPS from the solution. The singlet oxygen phosphorescence signal was detected right after the solvent refill and was remeasured $10 \mathrm{~min}$ later. The data acquisition in a single measurement lasted $12.5 \mathrm{~min}$.

Powder X-ray diffraction measurements were carried out on a Rigaku Ultima IV with a Rigaku DteX Ultra silicon microstrip detector with $\mathrm{Cu} / \mathrm{K} \alpha(\lambda=1.54178 \AA)$ radiation in a $2 \theta$ range of $7-50^{\circ}$ and scattered photons were recorded every $0.02^{\circ}$.

$\mathrm{X}$-ray Structure Determination. The single-crystal X-ray diffraction data set was measured on a Nonius Kappa CCD diffractometer equipped with a Bruker APEX II detector. For UPJS-10 and UPJS-12, Mo/K $\alpha$ radiation $(\lambda=0.71073 \AA)$ at $120(2)$ and $250(2) \mathrm{K}$ was used, respectively, while for UPJS$11, \mathrm{Cu} / \mathrm{K} \alpha$ radiation $(\lambda=1.54178 \AA)$ at $120(2) \mathrm{K}$ was used, and data reduction was carried out by the diffractometer software. The phase problem was solved by direct methods and refined with full-matrix least squares on $F^{2}$ using the Shelxl2018 program suite. ${ }^{65}$ Hydrogen atoms were refined isotropically and all other atoms were refined anisotropically. Hydrogen atoms located on aromatic carbon atoms were included in an ideal position with the $\mathrm{C}-\mathrm{H}$ bond fixed to 0.95 $\AA$ and $U_{\text {iso }}(\mathrm{H})$ assigned to $1.2 \mathrm{U}_{\text {eq }}$ of the adjacent carbon atom. The contribution of guest molecules located in the pores was subtracted by the SQUEEZE procedure in PLATON. ${ }^{66}$ The structure figures were drawn using DIAMOND software. ${ }^{67}$ Crystal data for UPJS-10, UPJS-11, and UPJS-12 are summarized in Table $S 1$ in the Supporting Information. Crystal structures of UPJS-10, UPJS-11, and UPJS-12 under the designation CCDC1998983, CCDC2041240, CCDC2041241, respectively, were deposited in Cambridge Crystallographic Data Centre (CCDC) and can be retrieved free of charge from https://www.ccdc.cam.ac.uk/structures.

\section{ASSOCIATED CONTENT}

\section{SI Supporting Information}

The Supporting Information is available free of charge at https://pubs.acs.org/doi/10.1021/acsomega.1c03327.
Single-crystal X-ray data for UPJS-10/11/12, selected bond lengths and bond angles, PXRD patterns, FT-IR and UV-VIS spectra, EDS analysis, and pore size distribution (PDF)

\section{AUTHOR INFORMATION}

\section{Corresponding Author}

Vladimír Zeleñák - Department of Inorganic Chemistry, Faculty of Science, P.J. Safárik University, Košice SK-041 54, Slovakia; (i) orcid.org/0000-0002-6118-1269;

Email: vladimir.zelenak@upjs.sk

\section{Authors}

Nikolas Király - Department of Inorganic Chemistry, Faculty of Science, P.J. Šafárik University, Košice SK-041 54, Slovakia

Nina Lenártová - Department of Inorganic Chemistry, Faculty of Science, P.J. Šafárik University, Košice SK-041 54, Slovakia

Adriana Zeleñáková - Institute of Physics, P. J. Šafárik University, Košice SK-04154, Slovakia

Erik Čižmár - Institute of Physics, P. J. Šafárik University, Kosice SK-04154, Slovakia

Miroslav Almáši - Department of Inorganic Chemistry, Faculty of Science, P.J. Safárik University, Košice SK-041 54, Slovakia

Vera Meynen - Laboratory of Adsorption and Catalysis, University of Antwerp, Wilrijk B-2610, Belgium;

(1) orcid.org/0000-0002-9867-6986

Andrej Hovan - Institute of Physics, P. J. Šafárik University, Košice SK-04154, Slovakia

Róbert Gyepes - Department of Inorganic Chemistry, Faculty of Science, Charles University, Prague CZ-128 43, Czech Republic; (1) orcid.org/0000-0002-2908-0425

Complete contact information is available at:

https://pubs.acs.org/10.1021/acsomega.1c03327

\section{Notes}

The authors declare no competing financial interest.

\section{ACKNOWLEDGMENTS}

This work was supported by the Scientific Grant Agency of the Slovak Republic (VEGA) under projects $1 / 0865 / 21$ and 1/ 0426/19, the Slovak Research and Development Agency under contract no. APVV-18-0197, and P. J. Safárik University under contract no. VVGS-2020-1667. N.K. thanks the National Scholarship Program for funding his internship at the Laboratory of Adsorption and Catalysis (LADCA) at the University of Antwerp. The authors thank Dr. J. Bednarčík from UPJS for PXRD measurements.

\section{REFERENCES}

(1) Ahmed, A.; Seth, S.; Purewal, J.; Wong-Foy, A. G.; Veenstra, M.; Matzger, A. J.; Siegel, D. J. Exceptional Hydrogen Storage Achieved by Screening Nearly Half a Million Metal-Organic Frameworks. Nat. Commun. 2019, 10, 1568.

(2) Haddad, S.; Abánades Lázaro, I.; Fantham, M.; Mishra, A.; Silvestre-Albero, J.; Osterrieth, J. W.; Kaminski Schierle, G. S.; Kaminski, C. F.; Forgan, R. S.; Fairen-Jimenez, D. Design of a Functionalized Metal-Organic Framework System for Enhanced Targeted Delivery to Mitochondria. J. Am. Chem. Soc. 2020, 142, 6661-6674

(3) Schoedel, A.; Ji, Z.; Yaghi, O. M. The Role of Metal-Organic Frameworks in a Carbon-Neutral Energy Cycle. Nat. Energy 2016, 1, 16034. 
(4) Wang, X. K.; Liu, J.; Zhang, L.; Dong, L.-Z.; Li, S.-L.; Kan, Y. H.; Li, D. S.; Lan, Y. Q. Monometallic Catalytic Models Hosted in Stable Metal-Organic Frameworks for Tunable $\mathrm{CO}_{2}$ Photoreduction. ACS Catal. 2019, 9, 1726-1732.

(5) Zhou, W.; Huang, D.-D.; Wu, Y.-P.; Zhao, J.; Wu, T.; Zhang, J.; Li, D.-S.; Sun, C.; Feng, P.; Bu, X. Stable Hierarchical BimetalOrganic Nanostructures as High- Performance Electrocatalysts for the Oxygen Evolution Reaction. Angew. Chem., Int. Ed. 2019, 58, $4227-4231$.

(6) Hu, Z.; Deibert, B. J.; Li, J. Luminescent Metal-Organic Frameworks for Chemical Sensing and Explosive Detection. Chem. Soc. Rev. 2014, 43, 5815-5840.

(7) Batten, S. R.; Champness, N. R.; Chen, X.-M.; Garcia-Martinez, J.; Kitagawa, S.; Öhrström, L.; O’Keeffe, M.; Paik Suh, M.; Reedijk, J. Terminology of Metal-Organic Frameworks and Coordination Polymers (IUPAC Recommendations 2013). Pure Appl. Chem. 2013, 85, 1715-1724.

(8) Cook, T. R.; Zheng, Y.-R.; Stang, P. J. Metal-Organic Frameworks and Self-Assembled Supramolecular Coordination Complexes: Comparing and Contrasting the Design, Synthesis and Functionality of Metal-Organic Materials. Chem. Rev. 2013, 113, 734-777.

(9) Chen, T.-H.; Popov, I.; Kaveevivitchai, W.; Miljanić, O. Š. Metal-Organic Frameworks: Rise of the Ligands. Chem. Mater. 2014, $26,4322-4325$.

(10) Lin, K. J. SMTP-1: The First Functionalized Metalloporphyrin Molecular Sieves with Large Channels. Angew. Chem., Int. Ed. Engl. 1999, 38, 2730-2732.

(11) Kosal, M. E.; Chou, J.-H.; Wilson, S. R.; Suslick, K. S. A Functional Zeolite Analogue Assembled from Metalloporphyrins. Nat. Mater. 2002, 1, 118-121.

(12) Suslick, K. S.; Bhyrappa, P.; Chou, J.-H.; Kosal, M. E.; Nakagaki, S.; Smithenry, D. W.; Wilson, S. R. Microporous Porphyrin Solids. Acc. Chem. Res. 2005, 38, 283-291.

(13) Gao, W.-Y.; Chrzanowski, M.; Ma, S. Metal-Metalloporphyrin Frameworks: a Resurging Class of Functional Materials. Chem. Soc. Rev. 2014, 43, 5841-5866.

(14) Chen, J.; Zhu, Y.; Kaskel, S. Porphyrin-Based Metal-Organic Frameworks for Biomedical Applications. Angew. Chem., Int. Ed. 2021, $60,5010-5035$

(15) De, S.; Devic, T.; Fateeva, A. Porphyrin and PhthalocyanineBased Metal Organic Frameworks Beyond Metal-Carboxylates. Dalton Trans. 2021, 50, 1166-1188.

(16) Almáši, M.; Zeleňák, V.; Gyepes, R.; Zukal, A.; Čejka, J. Synthesis, Characterization and Sorption Properties of Zinc(II) Metal-Organic Framework Containing Methanetetrabenzoate Ligand. Colloids Surf., A 2013, 437, 101-107.

(17) Almáši, M.; Zeleňák, V.; Zukal, A.; Kuchár, J.; Čejka, J. A Novel Zinc(Ii) Metal-Organic Framework with a Diamond-like Structure: Synthesis, Study of Thermal Robustness and Gas Adsorption Properties. Dalton Trans. 2016, 45, 1233-1242.

(18) Almáši, M.; Zeleňák, V.; Gyepes, R.; Bourrelly, S.; Opanasenko, M. V.; Llewellyn, P. L.; Cejka, J. Microporous Lead-Organic Framework for Selective $\mathrm{CO}_{2}$ Adsorption and Heterogeneous Catalysis. Inorg. Chem. 2018, 57, 1774-1786.

(19) Almáši, M.; Zeleňák, V.; Opanasenko, M. V.; Čejka, J. Efficient and Reusable $\mathrm{Pb}(\mathrm{II})$ Metal-Organic Framework for Knoevenagel Condensation. Catal. Lett. 2018, 148, 2263-2273.

(20) Almáši, M.; Zeleňák, V.; Gyepes, R.; Zauška, L'.; Bourrelly, S. A Series of Four Novel Alkaline Earth Metal-Organic Frameworks Constructed of $\mathrm{Ca}(\mathrm{II}), \mathrm{Sr}(\mathrm{II}), \mathrm{Ba}(\mathrm{II})$ Ions and Tetrahedral MTB Linker: Structural Diversity, Stability Study and Low/High-Pressure Gas Adsorption Properties. RSC Adv. 2020, 10, 32323-32334.

(21) Binnemans, K. Lanthanide-Based Luminescent Hybrid Materials. Chem. Rev. 2009, 109, 4283-4374.

(22) Bhattacharya, S.; Bala, S.; Mondal, R. Ln-MOFs Using a Compartmental Ligand with a Unique Combination of Hard-Soft Terminals and Their Magnetic, Gas Adsorption and Luminescence Properties. CrystEngComm 2019, 21, 5665-5672.
(23) Zhang, C.; Ma, X.; Cen, P.; Jin, X.; Yang, J.; Zhang, Y.-Q.; Ferrando-Soria, J.; Pardo, E.; Liu, X. A Series of Lanthanide(III) Metal-Organic Frameworks Derived from a Pyridyl-Dicarboxylate Ligand: Single-Molecule Magnet Behaviour and Luminescence Properties. Dalton Trans. 2020, 49, 14123-14132.

(24) Yi, X.-G.; Huang, J.-G.; Hu, R.-H.; Luo, Z.-G.; Pei, Y.-P.; Chen, W.-T. A Series of Thermal Stable Lanthanide Porphyrins with a Condensed Three-Dimensional Porous Open Framework: Gas Adsorption and Magnetic Properties. J. Porphyrins Phthalocyanines 2015, 19, 1072-1079.

(25) Chen, W.-T.; Luo, Q.-Y.; Xu, Y.-P.; Dai, Y.-K.; Huang, S.-L.; Guo, P.-Y. Hydrothermal Synthesis, Crystal Structure and Properties of a Thermally Stable Dysprosium Porphyrin with a ThreeDimensional Porous Open Framework. Inorg. Chem. Commun. 2014, 49, 16-18.

(26) Chen, W.-T.; Hu, R.-H.; Chen, H.-L.; Zhang, X.; Fu, H.-R. Synthesis, Characterization and Properties of a Gadolinium Tetra(4Sulfonatophenyl)Porphyrin. J. Iran. Chem. Soc. 2014, 12, 277-282.

(27) Hu, R.-H.; Yi, C.; Li, Y.; Zhang, Z.-X.; Lin, L.-Z.; Chen, W.-T. A Neodymium Tetra(4-Sulfonatophenyl)Porphyrin with a Flexible Three-Dimensional Framework. J. Porphyrins Phthalocyanines 2018, $22,325-330$.

(28) Diskin-Posner, Y.; Goldberg, I. Porphyrin Sieves. Designing Open Networks of Tetra(Carboxyphenyl)Porphyrins by Extended Coordination through Sodium Ion Auxiliaries. New J. Chem. 2001, 25, 899-904.

(29) Delgado-Lima, A.; Fonseca, A. M.; Machado, A. V. Novel Iridium-Pentafluorophenyl Porphyrin Complex. Mater. Lett. 2017, 200, 6-9.

(30) Zhang, W.; Jiang, P.; Wang, Y.; Zhang, J.; Zhang, P. Synthesis of Two Metal-Porphyrin Frameworks Assembled from Porphyrin Building Motifs, 5,10,15,20-Tetrapyridylporphyrin and Their Base Catalyzed Property. Inorg. Chem. Commun. 2015, 61, 100-104.

(31) Blatov, V. A.; Shevchenko, A. P.; Proserpio, D. M. Applied Topological Analysis of Crystal Structures with the Program Package ToposPro. Cryst. Growth Des. 2014, 14, 3576-3586.

(32) O’Keeffe, M.; Peskov, M. A.; Ramsden, S. J.; Yaghi, O. M. The Reticular Chemistry Structure Resource (RCSR) Database of, and Symbols for, Crystal Nets. Acc. Chem. Res. 2008, 41, 1782-1789.

(33) Alexandrov, E. V.; Shevchenko, A. P.; Blatov, V. A. Topological Databases: Why Do We Need Them for Design of Coordination Polymers? Cryst. Growth Des. 2019, 19, 2604-2614.

(34) Chen, W. T.; Hu, R. H.; Xu, Y. P.; Luo, Q. Y.; Dai, Y. K.; Huang, S. L.; Guo, P. Y. Photophysical and Electrochemical Properties of a Novel Lanthanide Tetra(4-Sulfonatophenyl)Porphyrin. J. Iran. Chem. Soc. 2015, 12, 937-942.

(35) Chen, W. T.; Hu, R. H.; Luo, Z. G.; Chen, H. L.; Liu, J. A New 3-D Lanthanide Porphyrin: Synthesis, Structure and Photophysical Properties. Chin. J. Struct. Chem. 2015, 34, 279-284.

(36) Demel, J.; Kubát, P.; Millange, F.; Marrot, J.; Císařová, I.; Lang, K. Lanthanide-Porphyrin Hybrids: from Layered Structures to Metal-Organic Frameworks with Photophysical Properties. Inorg. Chem. 2013, 52, 2779-2786.

(37) Ogilby, P. R. Singlet Oxygen: There Is Indeed Something New under the Sun. Chem. Soc. Rev. 2010, 39, 3181.

(38) Bregnhøj, M.; Westberg, M.; Jensen, F.; Ogilby, P. R. SolventDependent Singlet Oxygen Lifetimes: Temperature Effects Implicate Tunneling and Charge-Transfer Interactions. Phys. Chem. Chem. Phys. 2016, 18, 22946-22961.

(39) Couck, S.; Denayer, J. F.; Baron, G. V.; Tom, R.; Gascon, J.; Kapteijn, F. An Amine-Functionalized MIL-53 Metal-Organic Framework with Large Separation Power for $\mathrm{CO}_{2} / \mathrm{CH}_{4}$. J. Am. Chem. Soc. 2009, 131, 6326-6327.

(40) Gupta, S. K.; Shanmugan, S.; Rajeshkumar, T.; Borah, A.; Damjanović, M.; Schulze, M.; Wernsdorfer, W.; Rajaraman, G.; Murugavel, R. A Single-Ion Single-Electron Cerrous Magnet. Dalton Trans. 2019, 48, 15928-15935.

(41) Aguilà, D.; Barrios, L. A.; Velasco, V.; Roubeau, O.; Repollés, A.; Alonso, P. J.; Sesé, J.; Teat, S. J.; Luis, F.; Aromí, G. 
Heterodimetallic [ $\left.\mathrm{LnLn}^{\prime}\right]$ Lanthanide Complexes: Toward a Chemical Design of Two-Qubit Molecular Spin Quantum Gates. J. Am. Chem. Soc. 2014, 136, 14215-14222.

(42) Hino, S.; Maeda, M.; Yamashita, K.; Kataoka, Y.; Nakano, M.; Yamamura, T.; Nojiri, H.; Kofu, M.; Yamamuro, O.; Kajiwara, T. Linear Trinuclear Zn(II)-Ce(III)-Zn(II) Complex Which Behaves as a Single-Molecule Magnet. Dalton Trans. 2013, 42, 2683-2686.

(43) Xu, M.-X.; Meng, Y.-S.; Xiong, J.; Wang, B.-W.; Jiang, S.-D.; Gao, S. Magnetic Anisotropy Investigation on Light Lanthanide Complexes. Dalton Trans. 2018, 47, 1966-1971.

(44) Singh, S. K.; Gupta, T.; Ungur, L.; Rajaraman, G. Magnetic Relaxation in Single-Electron Single-Ion Cerium(III) Magnets: Insights from $\mathrm{Ab}$ Initio Calculations. Chem. - Eur. J. 2015, 21, 13812-13819.

(45) García-Palacios, J. L.; Gong, J. B.; Luis, F. Equilibrium Susceptibilities of Superparamagnets: Longitudinal and Transverse, Quantum and Classical. J. Phys.: Condens. Matter 2009, 21, 456006.

(46) Carlin, R. L. Magnetochemistry; 1st ed.; Springer-Verlag Berlin Heidelberg: Berlin, Germany, 2013.

(47) Bartolomé, E.; Alonso, P. J.; Arauzo, A.; Luzón, J.; Bartolomé, J.; Racles, C.; Turta, C. Magnetic Properties of the SevenCoordinated Nanoporous Framework Material Co(Bpy $)_{1.5}\left(\mathrm{NO}_{3}\right)_{2}$ (Bpy $=4,4$ '-Bipyridine). Dalton Trans. 2012, 41, 10382-10389.

(48) Aguilà, D.; Barrios, L. A.; Velasco, V.; Arnedo, L.; AliagaAlcalde, N.; Menelaou, M.; Teat, S. J.; Roubeau, O.; Luis, F.; Aromí, G. Lanthanide Contraction within a Series of Asymmetric Dinuclear [Ln $\left.{ }_{2}\right]$ Complexes. Chem. - Eur. J. 2013, 19, 5881-5891.

(49) Giansiracusa, M. J.; Al-Badran, S.; Kostopoulos, A. K.; Whitehead, G. F. S.; McInnes, E. J. L.; Collison, D.; Winpenny, R. E. P.; Chilton, N. F. Magnetic Exchange Interactions in Symmetric Lanthanide Dimetallics. Inorg. Chem. Front. 2020, 7, 3909-3918.

(50) Maniaki, D.; Perlepe, P. S.; Pilichos, E.; Christodoulou, S.; Rouzières, M.; Dechambenoit, P.; Clérac, R.; Perlepes, S. P. Asymmetric Dinuclear Lanthanide(III) Complexes from the Use of a Ligand Derived from 2-Acetylpyridine and Picolinoylhydrazide: Synthetic, Structural and Magnetic Studies. Molecules 2020, 25, 3153.

(51) Aguilà, D.; Velasco, V.; Barrios, L. A.; González-Fabra, J.; Bo, C.; Teat, S. J.; Roubeau, O.; Aromí, G. Selective Lanthanide Distribution within a Comprehensive Series of Heterometallic [LnPr] Complexes. Inorg. Chem. 2018, 57, 8429-8439.

(52) Layfield, R. A.; Murugesu, M. Lanthanides and Actinides in Molecular Magnetism; Wiley-VCH Verlag GmbH \&amp; Co. KGaA: Weinheim, Germany, 2015, pp. 154-184.

(53) Stoll, S.; Schweiger, A. EasySpin, a Comprehensive Software Package for Spectral Simulation and Analysis in EPR. J. Magn. Reson. 2006, 178, 42-55.

(54) Ikezaki, A.; Takahashi, M.; Nakamura, M. Equilibrium between $\mathrm{Fe}$ (IV) Porphyrin and Fe(III) Porphyrin Radical Cation: New Insight into the Electronic Structure of High-Valent Iron Porphyrin Complexes. Chem. Commun. 2013, 49, 3098.

(55) Bolzonello, L.; Albertini, M.; Collini, E.; Di Valentin, M. Delocalized Triplet State in Porphyrin J-Aggregates Revealed by EPR Spectroscopy. Phys. Chem. Chem. Phys. 2017, 19, 27173-27177.

(56) Shimizu, D.; Osuka, A. Porphyrinoids as a Platform of Stable Radicals. Chem. Sci. 2018, 9, 1408-1423.

(57) Mautner, F. A.; Bierbaumer, F.; Fischer, R. C.; Vicente, R.; Tubau, À.; Ferran, A.; Massoud, S. S. Structural Characterization, Magnetic and Luminescent Properties of Praseodymium(III)-4,4,4Trifluoro-1-(2-Naphthyl)Butane-1,3-Dionato(1-) Complexes. Crystals 2021, 11, 179.

(58) Kobets, M. I.; Khats'ko, E. N.; Dergachev, K. G.; Kalinin, P. S. Electronic Paramagnetic Resonance or Rare-Earth Ions $\mathrm{Yb}^{3+}, \mathrm{Pr}^{3+}$, $\mathrm{Dy}^{3+}$, and $\mathrm{Nd}^{3+}$ in Double Molybdates and Tungstenates. Low Temp. Phys. 2010, 36, 611-617.

(59) Király, N.; Zeleňák, V.; Zeleňáková, A.; Berkutova, A.; Almáši, M.; Gyepes, R.; Čižmár, E. Magnetic Properties of PraseodyniumOrganic Framework Containing $\mathrm{H}_{2}$ TPPS Ligand. Acta Phys. Pol., A 2020, 137, 770-772.
(60) Stevens, K. W. Matrix Elements and Operator Equivalents Connected with the Magnetic Properties of Rare Earth Ions. Proc. Phys. Soc., Sect. A 1952, 65, 209-215.

(61) Bleaney, B.; Stevens, K. W. H. Paramagnetic Resonance. Rep. Prog. Phys. 1953, 16, 108.

(62) Chilton, N. F.; Anderson, R. P.; Turner, L. D.; Soncini, A.; Murray, K. S. PHI: A Powerful New Program for the Analysis of Anisotropic Monomeric and Exchange-Coupled Polynuclear d- And fBlock Complexes. J. Comput. Chem. 2013, 34, 1164-1175.

(63) Eaton, S. S.; Eaton, G. R. Magnetic Susceptibility of Porphyrins. Inorg. Chem. 1980, 19, 1095-1096.

(64) Datta, S.; Hovan, A.; Jutková, A.; Kruglik, S. G.; Jancura, D.; Miskovsky, P.; Bánó, G. Phosphorescence Kinetics of Singlet Oxygen Produced by Photosensitization in Spherical Nanoparticles. Part II. The Case of Hypericin-Loaded Low-Density Lipoprotein Particles. J. Phys. Chem. B 2018, 122, 5154-5160.

(65) Sheldrick, G. M. Crystal Structure Refinement With SHELXL. Acta Crystallogr., Sect. C: Struct. Chem. 2015, 71, 3-8.

(66) Spek, A. L. Structure Validation in Chemical Crystallography. Acta Crystallogr., Sect. D: Struct. Biol. 2009, 65, 148-155.

(67) Brandenburg, K. DIAMOND 3.2e; Crystal Impact GbR: Bonn, Germany 2010. 